\title{
Nitric oxide-factor, which regulates proliferation and apoptosis in the adult brain of Amur sturgeon Acipenser schrenckii*
}

\author{
E. V. Pushchina ${ }^{1}$, D. K. Obukhov ${ }^{2}$ \\ ${ }^{1}$ A. V. Zhyrmunskii Institute of Marine Biology, Far Eastern Division, Russian Academy of Sciences, Vladivostok, Russia \\ ${ }^{2}$ St. Petersburg State University, St. Petersburg, Russia \\ Email: puschina@mail.ru
}

Received 29 August 2012; revised 30 September 2012; accepted 4 October 2012

\begin{abstract}
The distribution of proliferative zones, NO-producing cells and apoptosis areas in the medulla oblongata, cerebellum, optic tectum, thalamus and hypothalamus of Amur sturgeon Acipenser schrenckii was investigated, using techniques of immunoperoxidase staining of proliferating cell nuclear antigen (PCNA), neuronal nitric oxide synthase and TUNEL-labeling of fragmented DNA. It has been established, that in the sturgeon brain NO can act both as a cytotoxic proapoptogenic factor, and as a factor, which stimulates cell proliferation. The presence of NO-producing elements in somato- and viscerosensory areas of medulla oblongata, tectum, cerebellum and thalamus suppose, that in these brain areas NO constitutes apoptogenic factor, which induces the cells death in a territory of postmitotic neuroblasts, renders controlling effect on development and differentiating of chemosensory, visual, motor and hypophysotropic brain areas in postnatal ontogenesis. Maximal proliferating activity and high concentration of NO-ergic cells were revealed in external layers, adjoining to the medullar, cerebellar and tectum membranes, that allow to suppose NO participation in postnatal morphogenesis of these brain structures as a factor, which regulates cell proliferation. In sensory centers (tectum and nuclei of the $V$, VII, and $X$ nerves), significantly varying ratios of intensities of proliferation and apoptosis were found; this is indicative of dissimilar rates of growth and differentiation in visual and chemosensory centers of the sturgeon brain. Presence of NO-producing elements in the PCNA-immunola-beling and TUNELlabeling brain areas allow to consider NO as a factor, which balances processes of proliferation and apoptosis in the sturgeon brain.
\end{abstract}

\footnotetext{
${ }^{*}$ This work was supported by Grant of Far Eastern Branch of Russian Academy of Sciences № 12-III-A-06-095. Conflicts of interests: None declared.
}

Keywords: Adult Neurogenesis; Nitric Oxide; Apoptosis; Sturgeon; Neotenia; Development of Sensory Systems

\section{INTRODUCTION}

It is now generally accepted, that in the teleost brain the neurons permanently are occurring in the different brain areas, and promoting their growth in postembryonic period [1]. In some studies on different fish species, it was found that the corresponding proliferative centers are localized along the entire rostro-caudal brain axis [1,2]. The peculiarities of postnatal proliferation and manifesttations of apoptosis in the cerebellum were, in particular, examined in two fish species, a gymnotiform fish, Apteronotus leptorhynchus [3], and a cyprinoid fish, Danio rerio $[1,4]$. In whole, it should be recognized, that the mechanisms of postembryonic morphogenesis in the brain of fish remains little studied. Sturgeons form one of the most ancient groups of vertebrates; they are the most primitive evolutionary branch of the Actynopterygii. Evolution of sturgeons was, to a considerable extent, realized in a paedomorphosis mode characterized by relative slowdown of ontogenesis of organs and their systems. In the teleost fishes brain neuronal nitric oxide synthase was found in neurons and fibers, prevailing practically in all brain areas and in a spinal cord [5-10]. There is some, but not yet rigorous, evidence, that NADPH-diaphorase in the teleost fishes brain was localized in different types of neurons [5,8-10], glial cells: astrocyte and oligodendrocyte [11], and also in endotheliocyte [7] and tanicyte [12]. Thus, NO-producing systems in the teleost fish brain involve heterogeneous in morphological and functional aspects, population of neurons and glial cells. Presence of constitutive nitric oxide synthase in projection areas of majority sensory nerves in medulla oblongata and integrative brain centers show direct evidence of NO participation in the sense process regulation in low vertebrates brain. However up 
to date it is unknown, what influence NO render to the sensory system development in postembryonic ontogenesis. The results of experimental and morphological studies in teleost fishes have shown, that in CNS neurons NO participate in different functional mechanisms, which are connected with regeneration [13], differentiation $[14,15]$, cluster communication between neurons and glial cells [16], neuromorphogenesis [13,17], neurotransmission and cellular metabolism [18]. High content of NO in different types of the teleost brain cells differ substantially the teleost fishes from all other vertebrates, especially from the mammals, and may be connected with producing and death of large number neurons in postembryonic period of ontogenesis. Today the information about influence of NO-producing system on postembryonic development of the sturgeon's brain, on interrelations between embryonic and definitive parts in the structure of their CNS, and on relations between neotenic organization and differential development of the brain is absent.

The aim of this study is to find out the distribution of NO-producing sites in different brain areas and in addition, we attempted to define possible influences of NO on the processes of adult neurogenesis and apoptotic cell death in the brain of the Amur sturgeon Acipenser schrenckii.

\section{MATERIALS AND METHODS}

\subsection{Fishes Material}

In our study, we used nine 3-year-old individuals of the Amur sturgeon Acipenser schrenckii; body mass 900 to $1.100 \mathrm{~g}$, length 55 to $60 \mathrm{~cm}$. Fishes were obtained in 2011 from the Ryazanov experimental production fish hatchery. Fishes were anesthetized in a cuvette with $0.1 \%$ solution of tricaine methanesulfonate (MS-222; Sigma, USA) for 10 - $15 \mathrm{~min}$. The intracranial cavity of the immobilized fish was perfused, using a syringe, with a $4 \%$ solution of paraformaldehyde based on $0.1 \mathrm{M}$ phosphate buffer ( $\mathrm{pH} 7.2$ ).

\subsection{PCNA Immunohistochemistry}

To study the proliferative activity of cerebral cells, we used an indirect avidin-biotin-peroxidase (ABC technique) immunohistochemical staining of the proliferating cell nuclear antigen (PCNA). The fish brain fixed using the above technique was divided into several blocks, the myelencephalon at the level of nuclei of the V, VII, and $\mathrm{X}$ nerves, the cerebellum, a rostral part of the brainstem at the level of the isthmus, the thalamus with tectum hemispheres, and internal lobes of the hypothalamus. The obtained samples were embedded in paraffin according to a conventional technique [19]. Serial frontal slices $(20 \mu \mathrm{m}$ thick) prepared using a microtome were mounted on polylysine-covered glass slides. The material was deparaffined; to increase the membrane permeability, we used thermal treatment of the obtained preparations for $45 \mathrm{~min}$ at $95^{\circ} \mathrm{C}$ with the target retrieval solution (DAKO, USA). After cooling-down to room temperature, glass slides were rinsed in distilled water. To remove manifestations of nonspecific peroxidase activity, the slices were incubated in $1 \%$ solution of hydrogen peroxide for $5 \mathrm{~min}$ at $37^{\circ} \mathrm{C}$ and washed out three times in 0.1 $\mathrm{M}$ phosphate buffer ( $\mathrm{pH}$ 7.2). After these procedures, the slices were incubated with primary monoclonal mouse antibodies against PCNA (DAKO, USA) for 20 min under the same temperature conditions and washed out three times in $0.1 \mathrm{M}$ phosphate buffer. The slices were incubated with secondary biotin-conjugated mouse antibodies against rabbit immunoglobulins (LSAB 2 System, HRP; DAKO, USA) for $20 \mathrm{~min}$ at $37^{\circ} \mathrm{C}$ and then washed out three times of $0.1 \mathrm{M}$ phosphate buffer ( $\mathrm{pH}$ 7.2). Then, slices were incubated with the streptavidin visualization system (LSAB 2 System, HRP) under the same conditions $\left(20 \mathrm{~min}, 37^{\circ} \mathrm{C}\right)$ and washed out in $0.1 \mathrm{M}$ phosphate buffer. Reaction products were detected using diaminobenzidine (DAB) dissolved (to a concentration of 0.5 $\mathrm{mg} / \mathrm{ml}$ ) in the phosphate buffer; 1- or 2-ml aliquots were prepared. Before application, hydrogen peroxide based on the phosphate buffer $(0.1 \mathrm{M})$ was added to aliquots to the final concentration $(0.03 \%)$. The obtained preparations were kept for $5-7 \mathrm{~min}$ in a thermostat at $37^{\circ} \mathrm{C}$, to reach a clear visualization of the used marker (process was controlled under a microscope). Glass slides were washed out in distilled water; the slices were subjected to final staining with hematoxylin (Lilly-Mayer) for $30 \mathrm{sec}$, washed out with running water for 15 - $20 \mathrm{~min}$, dehydrated according to a standard technique, and embedded in balsam.

\subsection{TUNEL-Labeling}

To reveal apoptotic cells in the sturgeon brain, we used a technique for immunoperoxidase labeling of fragmented DNA chains, TUNEL. After 2-h-long fixation in 4\% solution of paraformaldehyde based on $0.1 \mathrm{M}$ phosphate buffer ( $\mathrm{pH}$ 7.2), dissected parts of the sturgeon brain were washed out for $24 \mathrm{~h}$ in 0.1 . M phosphate buffer. Then, these samples were put in $30 \%$ solution of sucrose based on phosphate buffer $(0.1 \mathrm{M})$ for cryoprotection and kept in this solution up to full immersion. Frontal and horizontal slices $(20 \mu \mathrm{m}$ thick) were prepared using a freezing microtome. To identify TUNEL-positive structures, we used a immunoperoxidase identification system, ApopTag Peroxidase in Situ Apoptosis Detection Kit (Chemicon International Inc., USA). For blocking endogenous peroxidase, the slices were incubated in $1 \%$ 
solution of hydrogen peroxide for $3 \mathrm{~min}$ and then washed out two times for $5 \mathrm{~min}$ in phosphate buffer. The slices were covered with a smoothing buffer $(75 \mu \mathrm{l})$ and kept for $10 \mathrm{sec}$ at room temperature. Then, the slices were slightly dried, subjected to the action of TdT enzyme (55 $\mu \mathrm{l} / 5 \mathrm{~cm}^{2}$ ), incubated in a humid chamber for $1 \mathrm{~h}$ at $37^{\circ} \mathrm{C}$, and immersed in a stop buffer for $10 \mathrm{~min}$. The slices were washed out in phosphate buffer at room temperature (three times for $1 \mathrm{~min}$ with changing of the solution), again dried, covered with antidioxygenin conjugate (65 $\mu 1 / 5 \mathrm{~cm}^{2}$ ), and incubated in a humid chamber for $30 \mathrm{~min}$. To detect the reaction products, cerebral slices were incubated in the substrate for identification of peroxidase (VIP Substrate Kit; Vector Labs, USA) with control of the development of color under a microscope, washed out in three changes of phosphate buffer, and mounted on glass slides. The cell nuclei were subjected to final staining with methyl green according to the technique of Brasher [19]. The preparations obtained were dewatered using a conventional technique and embedded in balsam.

\section{4. nNOS Immunohistochemistry}

To reveal localization of NO-producing neurons and fibers in the sturgeon brain, we used a technique of indirect streptavidinbiotin immunohistochemical labeling of NOS. The slices were incubated with primary polyclonal rabbit antibodies against NOS (ICN Biomedicals, USA; dilution 1:5000) at $4^{\circ} \mathrm{C}$ for $24 \mathrm{~h}$. After three washings out in phosphate buffer, the slices were incubated with secondary biotin-conjugated goat antibodies against rabbit immunoglobulins (Biomedicals, Germany) at room temperature for $2 \mathrm{~h}$. The material was washed out three times in phosphate buffer. Then, the slices were incubated in the presence of the streptavidinperoxidase complex (Biomedicals, Germany) at room temperature for $2 \mathrm{~h}$ and again washed out three times in phosphate buffer. Immunohistochemical reactions were visualized using a standard avidinbiotin system (ABC; Vectastain Elite ABC Kit; Vector Laboratories, USA). To identify the reaction products, the slices were incubated in a substrate for detection of peroxidase (VIP Substrate Kit; Vector Laboratories, USA); the process of staining was controlled under a microscope. Then, the slices were washed out in three changes of phosphate buffer, mounted on slides, dehydrated using a standard technique, and embedded in balsam. To estimate the specificity of the immunohistochemical reaction, we used a technique of negative control. The sturgeon brain slices were incubated in a medium containing $1 \%$ nonimmune horse serum (instead of primary antibodies) for $48 \mathrm{~h}$, and then all procedures were performed as was described above. In all control experiments, the immunopositivity in the studied cells was absent.

\subsection{Statistic Analysis}

Morphometric processing was performed using an inverted-stage microscope, Axiovert $200 \mathrm{M}$, equipped with a module, ApoTome, and digital cameras, Axio Cam MRM and Axio Cam HRC (Carl Zeiss, Germany). The measurements were performed at $\times 400$ magnification in five randomly chosen fields of vision for each studied region. The proliferation index (PI) and apoptosis index (AI) were calculated per $1 \mathrm{~mm}^{2}$ of the section using the following formulas:

$$
\begin{aligned}
& \mathrm{PI}=\frac{n \text { of the PCNA }- \text { positive nuclei }}{\text { total } n \text { of the nuclei }} \cdot 100 \% \text { and } \\
& \mathrm{AI}=\frac{n \text { of TUNEL }- \text { positive fragments }}{\text { total } n \text { of nuclei }} \cdot 100 \% .
\end{aligned}
$$

Parametric comparison (Student's $t$-test) was used for estimation of the intergroup differences. The data obtained were processed using Statistica and Excel software. Numerical data are presented below as means \pm s.e.m.

\section{RESULTS}

\subsection{Labeling of PCNA}

In the myelencephalon we studied regions of the V, VII, and $\mathrm{X}$ nerves nuclei; on the external surface of the myelencephalon, typical thickenings (hypertrophied lobes of the above nerves) corresponding to these nuclei. Within the territory of these lobes, we examined periventricular, subventricular, and deeper regions of the myelencephalon, namely the interfascicular region, medial reticular formation (MRF), and perinuclear parts (adjacent to the nuclei) localized far from the opening of the cerebral ventricle, as well as cells of the somatovisceral longitudinal column forming the nuclei of the V, VII, and $\mathrm{X}$ nerves.

In the periventricular myelencephalon region, PCNA-ir cells formed a cellular layer corresponding, by its morphological peculiarities, to the neuroepithelium (Figure 1(A)). This layer included morphologically heterogeneous cells; among such units, we classified three main types. The morphological parameters of PCNA-ir cells in the periventricular region of the myelencephalon are mentioned in Table 1. Within this region, we found small practically round units with mean large/small diameters of 7.8/7.0 $\mu \mathrm{m}$, as well as oval $(11 / 7.5 \mu \mathrm{m})$, and elongated $(16 / 7.2 \mu \mathrm{m})$ units. Therefore, all the labeled PCNA-ir neurons in this region differed from each other only in the values of the large diameters of the somata, while small diameters were nearly the same. The PI for the periventricular zone of the myelencephalon was, on average, $21.0 \% \pm 1.3 \%$ (Table 1). In the subventricular region, mainly in caudal regions of the myelencephalon, 
Table 1. Morphometric characteristics of PCNA-, nNOS- and TUNEL-immunopositive (ip) elements and the proliferation and apoptosis indices (PI and AI, Respectively; $\mathrm{M} \pm$ s.e.m.) in the brain of the Amur sturgeon Acipenser schrenckii.

\begin{tabular}{|c|c|c|c|c|c|}
\hline Brain subdivisions & $\begin{array}{c}\text { Dimensions of PCNA-ip } \\
\text { cells, } \mu \mathrm{m}\end{array}$ & PI, \% & $\begin{array}{c}\text { Dimensions of TUNEL-ip } \\
\text { elements, } \mu \mathrm{m}\end{array}$ & AI, $\%$ & $\begin{array}{c}\text { Dimensions of nNOS-ip } \\
\text { cells, } \mu \mathrm{m}\end{array}$ \\
\hline \multicolumn{6}{|c|}{ Myelencephalon } \\
\hline Periventricular region & $\begin{array}{c}7.8 \pm 0.4 / 7.0 \pm 1.1 \\
11.1 \pm 0.8 / 7.5 \pm 1.4 \\
14.5 \pm 1.5 / 7.2 \pm 1.0\end{array}$ & $21 \pm 1.3$ & $\begin{array}{l}6.4 \pm 0.3 / 5.9 \pm 0.3 \\
8.9 \pm 0.5 / 6.2 \pm 0.4\end{array}$ & $9 \pm 0.2$ & $\begin{array}{c}7.6 \pm 0.7 / 7.1 \pm 1.3 \\
9.4 \pm 0.3 / 8.5 \pm 0.2 \\
12.8 \pm 1.0 / 7.1 \pm 0.8\end{array}$ \\
\hline $\begin{array}{l}\text { Deep layers of the } \\
\text { myelencephalon }\end{array}$ & $\begin{array}{c}7.9 \pm 1.1 / 5.7 \pm 0.3 \\
11.5 \pm 1.4 / 9.1 \pm 2.3\end{array}$ & $8.5 \pm 0.2$ & - & - & $\begin{array}{c}9.5 \pm 0.4 / 9.4 \pm 0.2 \\
11.7 \pm 1.0 / 8.6 \pm 1.4 \\
14.1 \pm 0.6 / 12.1 \pm 0.8\end{array}$ \\
\hline $\begin{array}{l}\text { Cells of the medial reticular } \\
\text { formation (MRF) at the } \\
\text { isthmus level }\end{array}$ & - & - & $\begin{array}{c}31.9 \pm 2.6 / 28.6 \pm 3.1 \\
17.5 \pm 4.4 / 12.3 \pm 1.5 \\
8.3 \pm 1.8 / 5.1 \pm 0.6\end{array}$ & $8.9 \pm 0.3$ & $\begin{array}{c}28.3 \pm 4.1 / 22.3 \pm 5.32 \\
0.5 \pm 2.5 / 15.5 \pm 2.6 \\
16.6 \pm 2.3 / 12.1 \pm 3.1\end{array}$ \\
\hline $\begin{array}{l}\text { MRF at the level of the } \\
\text { nucleus of the } V \text { nerve }\end{array}$ & - & - & $\begin{aligned} 15.7 & \pm 1.4 / 11.7 \pm 1.5 \\
9.0 & \pm 2.3 / 6.5 \pm 0.6 \\
6.2 & \pm 0.2 / 5.0 \pm 0.6\end{aligned}$ & $10.6 \pm 0.4$ & $\begin{array}{c}16.8 \pm 2.7 / 12.3 \pm 1.4 \\
9.6 \pm 1.4 / 7.2 \pm 0.4 \\
6.1 \pm 0.2 / 5.4 \pm 0.5\end{array}$ \\
\hline Interfascicular cells & - & - & $\begin{array}{c}30.9 \pm 3.3 / 15.5 \pm 2.1 \\
22.4 \pm 1.3 / 11.0 \pm 1.2 \\
12.3 \pm 1.4 / 8.7 \pm 1.5\end{array}$ & $9 \pm 0.4$ & $\begin{array}{l}36.2 \pm 7.3 / 24.4 \pm 6.3 \\
28.7 \pm 4.5 / 22.7 \pm 5.4 \\
16.6 \pm 3.2 / 13.2 \pm 2.7\end{array}$ \\
\hline $\begin{array}{l}\text { Cells of the somatosensory } \\
\text { column }\end{array}$ & - & - & $8.5 \pm 1.2 / 5.6 \pm 0.4$ & $3.4 \pm 0.3$ & $\begin{array}{l}39.3 \pm 4.3 / 28.1 \pm 2.3 \\
48.3 \pm 6.5 / 28.7 \pm 3.6 \\
55.6 \pm 8.2 / 43.4 \pm 5.7\end{array}$ \\
\hline Cells of the external zone & $\begin{array}{c}6.7 \pm 0.2 / 5.7 \pm 0.9 \\
8.0 \pm 0.7 / 6.1 \pm 0.9 \\
11.3 \pm 0.2 / 8.7 \pm 1.3\end{array}$ & $4.5 \pm 0.3$ & - & - & $\begin{array}{c}6.8 \pm 0.3 / 6.0 \pm 0.9 \\
8.1 \pm 0.7 / 6.0 \pm 0.7 \\
10.6 \pm 1.2 / 7.3 \pm 2.5\end{array}$ \\
\hline Molecular layer & $\begin{array}{c}8.0 \pm 0.9 / 6.3 \pm 0.9 \\
10.3 \pm 0.6 / 7.8 \pm 0.9\end{array}$ & $9.9 \pm 0.7$ & $\begin{array}{l}6.7 \pm 2.2 / 5.3 \pm 2.0 \\
9.9 \pm 1.3 / 7.0 \pm 1.2\end{array}$ & $12.5 \pm 0.9$ & $\begin{array}{l}6.7 \pm 1.4 / 5.3 \pm 0.9 \\
8.8 \pm 0.7 / 6.8 \pm 0.7\end{array}$ \\
\hline Ganglionary layer & - & - & $12.5 \pm 1 / 10.2 \pm 0.5$ & $6 \pm 0.5$ & $\begin{array}{c}14.8 \pm 0.8 / 11.2 \pm 0.3 \\
17.5 \pm 1.3 / 8.9 \pm 0.6\end{array}$ \\
\hline Granular layer & $\begin{array}{c}7.8 \pm 0.4 / 6.5 \pm 1.4 \\
12.1 \pm 1.8 / 8.2 \pm 1.4\end{array}$ & $15.8 \pm 0.6$ & $\begin{array}{c}22.8 \pm 1.2 / 17.8 \pm 1 \\
16.0 \pm 0.8 / 10.8 \pm 0.5 \\
11.9 \pm 0.6 / 9.2 \pm 0.4 \\
8.8 \pm 0.9 / 7.2 \pm 1.5\end{array}$ & $0.77 \pm 0.1$ & $6.8 \pm 0.8 / 5.5 \pm 1.0$ \\
\hline \multicolumn{6}{|c|}{ Tectum } \\
\hline Periventricular layer & $\begin{array}{c}7.8 \pm 0.4 / 7.0 \pm 1.1 \\
10.8 \pm 0.9 / 7.4 \pm 1.2 \\
14.3 \pm 1.2 / 7.3 \pm 1.0\end{array}$ & $12.1 \pm 1.4$ & $\begin{array}{l}3.6 \pm 0.4 / 2.3 \pm 0.2 \\
6.0 \pm 0.7 / 4.7 \pm 0.5 \\
7.9 \pm 0.8 / 7.1 \pm 0.3\end{array}$ & $2 \pm 0.3$ & $\begin{array}{l}6.8 \pm 0.4 / 5.8 \pm 1.1 \\
9.2 \pm 0.6 / 7.1 \pm 1.1\end{array}$ \\
\hline Marginal layer & $\begin{array}{l}6.7 \pm 0.2 / 5.7 \pm 0.9 \\
8.0 \pm 0.7 / 6.1 \pm 0.9\end{array}$ & $17.8 \pm 1.5$ & $6.9 \pm 1.3 / 5.7 \pm 0.6$ & $15 \pm 1.6$ & $\begin{array}{l}6.4 \pm 0.5 / 5.9 \pm 0.7 \\
8.2 \pm 0.3 / 6.3 \pm 0.5\end{array}$ \\
\hline Optic layer & $7.2 \pm 0.2 / 6.8 \pm 0.4$ & $5.4 \pm 0.3$ & $6.8 \pm 0.6 / 5.4 \pm 0.2$ & $1.5 \pm 0.2$ & - \\
\hline Central gray layer & $\begin{array}{l}10.3 \pm 0.6 / 7.8 \pm 0.9 \\
12.1 \pm 0.8 / 8.2 \pm 1.4\end{array}$ & $5.6 \pm 0.3$ & $\begin{array}{l}7.8 \pm 0.5 / 7.3 \pm 0.2 \\
9.9 \pm 1.3 / 7.0 \pm 1.2\end{array}$ & $8 \pm 0.4$ & $\begin{array}{l}17.3 \pm 1.2 / 7.8 \pm 2.0 \\
11.1 \pm 0.8 / 7.2 \pm 0.7\end{array}$ \\
\hline $\begin{array}{l}\text { External cellular/fibrous } \\
\text { layer }\end{array}$ & $\begin{array}{l}16.5 \pm 1.5 / 7.2 \pm 1.0 \\
12.1 \pm 0.8 / 8.2 \pm 1.4\end{array}$ & $6.3 \pm 0.4$ & $7.4 \pm 0.3 / 7.0 \pm 0.2$ & $9 \pm 0.5$ & $\begin{array}{c}14.3 \pm 1.2 / 6.2 \pm 1.2 \\
10.1 \pm 1.2 / 7.8 \pm 1.1 \\
7.2 \pm 0.8 / 5.9 \pm 0.3\end{array}$ \\
\hline Inner fibrous layer & $\begin{array}{c}10.3 \pm 0.6 / 7.8 \pm 0.9 \\
8.0 \pm 0.7 / 6.1 \pm 0.9\end{array}$ & $8.1 \pm 0.3$ & $7.5 \pm 0.3 / 7.1 \pm 0.3$ & $20 \pm 2.3$ & $\begin{array}{l}9.7 \pm 0.4 / 6.2 \pm 0.9 \\
7.2 \pm 0.5 / 5.3 \pm 0.4\end{array}$ \\
\hline
\end{tabular}


Continued

\begin{tabular}{|c|c|c|c|c|c|}
\hline \multicolumn{6}{|c|}{ Thalamus } \\
\hline Periventricular region & $\begin{array}{c}7.8 \pm 0.4 / 7.0 \pm 1.1 \\
14.5 \pm 1.5 / 7.3 \pm 1.0\end{array}$ & $12 \pm 1.1$ & $6.4 \pm 0.1 / 5.6 \pm 0.2$ & $7.6 \pm 0.3$ & $\begin{array}{c}14.7 \pm 1.5 / 7.3 \pm 1.0 \\
8.1 \pm 0.5 / 7.3 \pm 0.4\end{array}$ \\
\hline Subventricular region & $9.0 \pm 0.9 / 7.3 \pm 0.9$ & $4.3 \pm 0.5$ & $6.7 \pm 0.1 / 5.6 \pm 0.2$ & $2.8 \pm 0.5$ & $\begin{array}{c}8.7 \pm 0.6 / 7.3 \pm 0.5 \\
10.0 \pm 0.4 / 7.3 \pm 0.3\end{array}$ \\
\hline Dorsal thalamic nuclei & $\begin{array}{c}9.1 \pm 1.3 / 7.7 \pm 0.5 \\
10.1 \pm 0.2 / 7.3 \pm 0.6\end{array}$ & $7.6 \pm 0.4$ & $\begin{array}{c}8.5 \pm 0.9 / 6.5 \pm 0.8 \\
11.5 \pm 0.3 / 7.9 \pm 2.1 \\
13.4 \pm 0.2 / 8.7 \pm 2.1\end{array}$ & $13 \pm 1.3$ & $\begin{array}{c}9.1 \pm 1.3 / 7.7 \pm 0.5 \\
12.4 \pm 0.7 / 7.8 \pm 0.6\end{array}$ \\
\hline \multicolumn{6}{|c|}{ Hypothalamus } \\
\hline Periventricular region & $\begin{array}{c}7.6 \pm 0.2 / 7.2 \pm 0.8 \\
14.5 \pm 1.5 / 7.3 \pm 1.0\end{array}$ & $9.6 \pm 0.6$ & $6.3 \pm 0.2 / 5.9 \pm 0.3$ & $3 \pm 0.4$ & $\begin{array}{c}8.1 \pm 0.8 / 7.2 \pm 0.5 \\
15.5 \pm 1.5 / 7.3 \pm 1.0\end{array}$ \\
\hline Subventricular region & $9.1 \pm 0.7 / 7.4 \pm 0.9$ & $6.6 \pm 0.3$ & $7.1 \pm 0.2 / 5.8 \pm 0.2$ & $6 \pm 0.3$ & $\begin{array}{c}8.7 \pm 0.6 / 7.3 \pm 0.5 \\
11.0 \pm 0.6 / 6.9 \pm 0.6\end{array}$ \\
\hline Lateral hypothalamus & $\begin{array}{c}9.2 \pm 0.9 / 7.3 \pm 0.9 \\
12.4 \pm 0.7 / 8.8 \pm 1.4\end{array}$ & $4 \pm 0.5$ & $\begin{array}{l}14.8 \pm 0.7 / 11.2 \pm 3.0 \\
19.1 \pm 1.3 / 13.2 \pm 1.2 \\
28.4 \pm 2.5 / 14.5 \pm 1.9\end{array}$ & $18 \pm 2.0$ & $\begin{array}{c}9.9 \pm 0.6 / 7.2 \pm 0.6 \\
13.4 \pm 0.4 / 8.2 \pm 1.1\end{array}$ \\
\hline Ventral hypothalamus & $\begin{array}{c}9.1 \pm 0.7 / 7.4 \pm 0.9 \\
11.8 \pm 0.8 / 8.1 \pm 1.4\end{array}$ & $4.2 \pm 0.4$ & $\begin{array}{c}11.5 \pm 0.3 / 7.9 \pm 2.1 \\
13.3 \pm 0.4 / 10.2 \pm 2.0\end{array}$ & $6.8 \pm 0.3$ & $\begin{array}{c}9.4 \pm 0.6 / 7.8 \pm 0.3 \\
12.8 \pm 0.5 / 7.6 \pm 1.4\end{array}$ \\
\hline
\end{tabular}

Footnotes. Dimensions of ip elements are presented as mean values of their greater and smaller diameters separated by a slash. In deep layers of the myelencephalon, PCNA-ip cells were found in the MRF at levels of the isthmus, nuclei of the V, VII, and X nerves, and interfascicular region.

we observed two types of PCNA-ip cells (Table 1). In the rostral part of the brainstem, the PIs in the subventricular and caudal zones were $3.3 \%$ and $14.3 \%$, respecttively. In the projection region of the trigeminal nerve, PCNA immunolocalization was observed in cells of the periventricular zone adjacent to the nucleus of $\mathrm{V}$ nerve, as well as in single cells of the perinuclear zone (Figure 1(b)). For these regions, the PI values were 6.3 and $9.3 \%$, respectively (Figure 2(A)). In the region of projection of the facial nerve, PCNA immunopositivity was also observed mostly in the periventricular zone; however, large weakly labeled PCNA cells prosessing processes were observed in the nucleus per se. These units did not belong to the population of periventricular neuroblasts (Figure 1(C)). The PI values for the nucleus of the facial nerve and for the adjacent perinuclear region were 9.6 and 5.6\%, respectively (Figure 2(A)). Most PCNA-ip cells localized in deep layers of the myelencephalon were classified as belonging to different regions of the reticular formation, to the rostral part (at the level of the isthmus and nucleus of the trigeminal nerve) and caudal one (at the level of projection of the vagus nerve) (Table 1). For these zones in the rostral and caudal regions of the myelencephalon, the PI values were $8.5 \%$ and $15.6 \%$, respectively. In the region of projection of the $\mathrm{X}$ nerve, the overwhelming majority of PCNA-ip cells were localized periventricularly, and the PI was very high (23.7\%). In the subventricular region, the number of PCNA-ir cells was considerably smaller (PI 4.9\%), while this index was $5.7 \%$ in the deep layer (Figure 2(B)). In the sturgeon myelencephalon, PCNA-ip elements were also observed near the external surface adjacent to the pia matter (Figure 1(D)). These immunopositive cells were divided into three types; among them, two cell types were also common for other regions, while one type was formed by smaller units (Table 1).

In the cerebellum, PCNA-ip cells were found in the granular and molecular layers. In the dorsal part of the cerebellar body, the maximum number of small round and oval PCNA-ip cells was observed (Table 1). The PI values for granular-layer cells of the caudal and ventral parts of the cerebellar body were $15.6 \%$ and $7.6 \%$, respectively. In different regions of the cerebellar body, the values of this index of proliferative activity (PI) varied (Table 1). In the rostral part, this index for cells localized in the granular layer was, on the whole, lower (in the dorsal and ventral regions, $9.6 \%$ and $7.6 \%$, respecttively). In various parts of the molecular layer of the cerebellar body, the number of PCNA-ip cells also differed from each other (Table 1). In the rostral part, the PI was $10 \%$, while in the caudal part this index varied from $8.3 \%$ to $7.6 \%$. In the cerebellar valve, the majority of PCNA-ip cells were localized in the periventricular layer close to the opening of the intertectal ventricle (Figure 1(E)). In the molecular layer of the valve, we found small PCNA-ip cells; the PI for these cells was $8.3 \%$. In the central part of the valve, large weakly labeled PCNAip cells (Figure 1(E)) that could not be classified as typical PCNA-ip units were also observed.

In the tectum, the number of labeled PCNA cells demonstrated clearly pronounced differences. Such dissimilarities were clear, on the one hand, in rostral and 


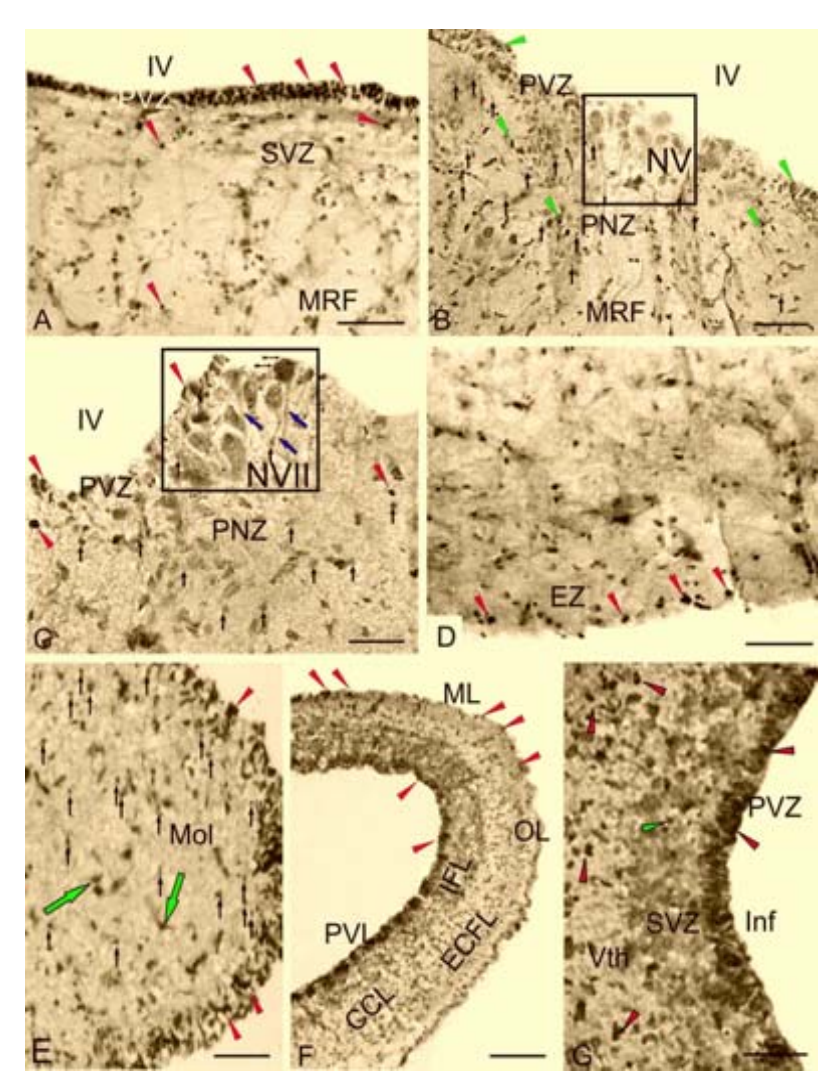

Figure 1. Immunolocalisation of proliferating cell nuclear antigen (PCNA) in the Amur sturgeon Acipenser schrenckii brain. (A) Cross section of dorsal parts of the myelencephalon at the caudal level. Triangular red arrows indicate PCNA-ip cells in the periventricular (PVZ) and subventricular (SVZ) zones and at the level of the medial reticular formation (MRF); (B) Section through the nucleus of the trigeminal $(\mathrm{V})$ nerve (region of the nucleus (NV) is outlined by a rectangle); triangular green arrows indicate PCNA-ip cells, black arrows indicate immunonegative cells; (C) Section through the nucleus of the facial (NVII) nerve (outlined by a rectangle); blue arrows indicate processes of immunonegative cells of the nucleus; two small figured arrows indicate two daughter cells possessing a common process; (D) Fragment of the myelencephalon external zone (EZ) adjacent to the cerebral covers; (E) Section of the valve of the cerebellum; green arrows indicate large slightly labeled PCNA-ip cells; (F) Section through the tectum; (G) Section at the level of the ventral thalamus, green arrow indicate immunonegative cell in subventricular area. Designation: IV-fourth ventricle; PNZ-perinuclear zone; MoL-Molecular layer; PVL-periventricular, IFL-inner fibrous, CCL-central cellular, ECFL-external cellular/fibrous, OL-optic, and MLmarginal layers; VH-ventral halamus, Inf-infundibulum. Scale: (A), (B), (D), (E) $-100 \mu \mathrm{m},(\mathrm{C}),(\mathrm{G})-50 \mu \mathrm{m},(\mathrm{F})-200 \mu \mathrm{m}$.

caudal parts of this structure and, on the other hand, in medial and lateral zones (Figure 3). Most PCNA-ip cells were localized in the tectal PVL (Figure 1(F)) where we found all patterns of cells typical of the periventricular zone of the myelencephalon (Table 1). In the medial region, the relative number of proliferating cells within the PVL was more than two times greater than in the

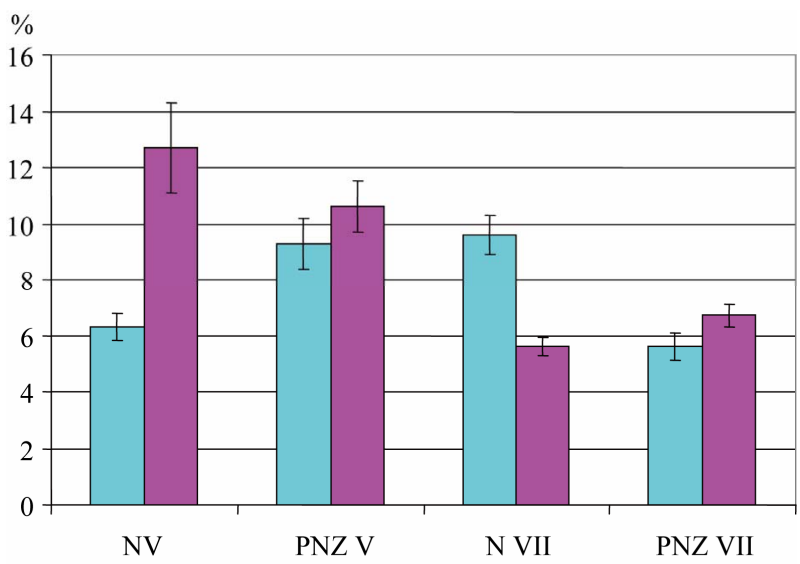

(A)

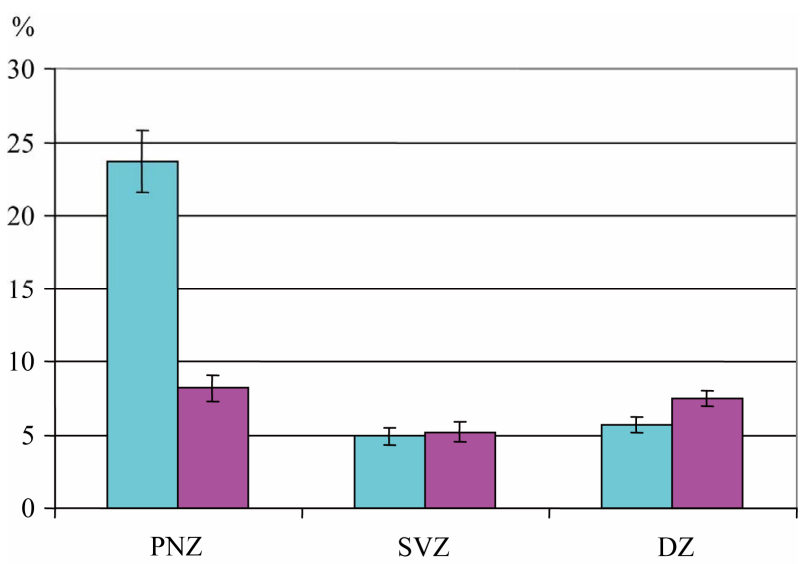

(B)

Figure 2. Intensity of the processes of proliferation and apoptosis in different parts of the myelencephalon of the Amur sturgeon Acipenser schrenckii. Data are shown as $\mathrm{M} \pm \mathrm{m}$. Abscissa axis: (A) In the nuclei of trigeminal and facial nerves (NV and NVII, respectively) and perinuclear zones adjacent to these nuclei (PNZ V and PNZ VII, respectively); (B) In the lobe of the X nerve. PVZ, SVZ, and DZ-periventricular, subventricular, and deep zones, respectively. Ordinate axis-Proliferation index, PI (blue columns) and apoptosis index, AI (pink columns), $\%$.

lateral region; the PI values in these zones were $17.6 \%$ and $7.0 \%$, respectively (Figure 3). Highly immunopositive cells were found near the external border of the marginal layer (ML). Rather high PI values in the lateral and medial zones were nearly the same $(17.0 \%$ and $18.6 \%$, respectively; Figures 1(F) and 3). In the optic layer (OL), the number of stained PCNA-ip cells was smaller. In the medial and lateral parts, the PI values were $4.3 \%$ and $6.6 \%$, respectively. In the central cellular layer (CCL) and external cellular/fibrous layer (ECFL), the number of PCNA-ip cells in the lateral zone appreciably exceeded that in the medial parts (Figure 3). Therefore, morphometric analysis showed that the majority of PCNA-ip cells in the medial part of the tectum are concentrated in the PVL and ML, while their numbers were relatively 


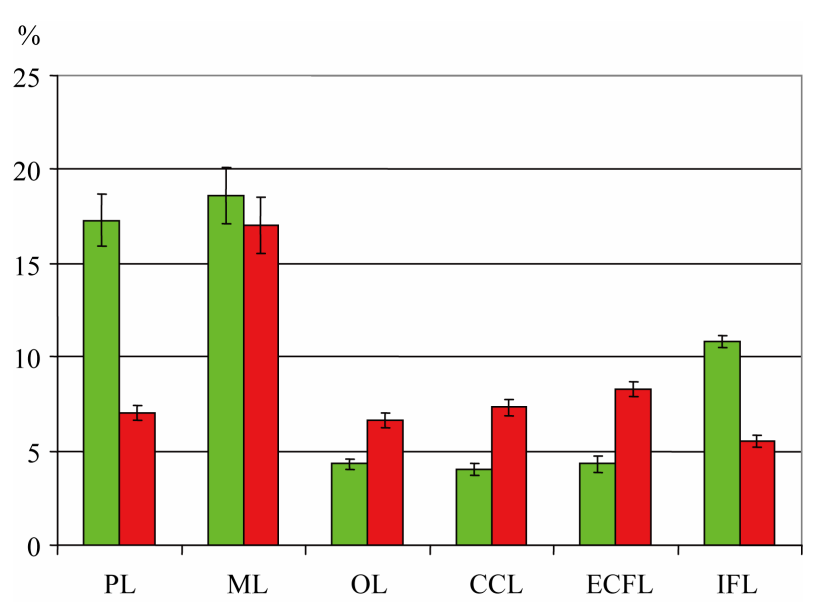

Figure 3. Intensity of proliferative activity in the tectum of the Amur sturgeon Acipenser schrenckii brain. Data are shown as $\mathrm{M} \pm \mathrm{m}$. Abscissa axis, PCNA activity in the layers of the optic tectum: PVL-periventricular, IFL-inner fibrous, CCL-central cellular, ECFL-external cellular/fibrous, OL-optic, and MLmarginal layers. Ordinate axis: Proliferation index (PI), \%. Green and red columns correspond to the PI values in the medial and lateral zones of the tectum, respectively.

small in the CCL, ECFL, and OL (Figure 3). In the lateral zone, most PCNA-ip cells were found in the ML, while in the PVL their number was smaller. At the same time, a considerable proportion of the PCNA-ip cells were localized in the deep layer of the tectum.

In the thalamus, most PCNA-ip cells were localized in the periventricular region (mean PI value, $12 \% \pm 1.1 \%$ ) and deep layers (Figure 1(G)). On the territory of the dorsal thalamic nuclei adjacent to the Meynert's retroflex bundle, we also found weakly labeled PCNA-ip cells. The PI value for this region was $7.6 \% \pm 0.4 \%$ (Table 1). In the subventricular region, we found relatively rare PCNA-ip cells (PI $4.3 \pm 0.5 \%$ ) and rather numerous immunonegative units (Figure 1(G)). In the hypothalamus, the relative number of PCNA-ip cells in the periventricular region was greater (PI 9.6\% $\pm 0.6 \%$ ) than that in the subventricular region (PI 6.6\% $\pm 0.3 \%$ ). In deep layers of the lateral and ventral hypothalamus, the normalized number of PCNA-ip cells was $4.0 \%$ to $4.2 \%$ (Table 1).

\subsection{TUNEL Labeling}

In the sturgeon myelencephalon, TUNEL-labeled elements were indentified in the periventricular and subventricular zones, longitudinal somatovisceral neuronal column, and reticular formation (Figures 4(A) and (B)). TUNEL-positive structures in this cerebral part demonstrated different stages of the apoptotic process. Among the corresponding neurons, we identified both cells with fragmented chromatin and units at later stages of the above-mentioned process (Figure 4(C)). In the vicinity of large reticular formation neurons containing clearly distinguishable fragmented TUNEL-labeled chromatin, we frequently observed numerous glial cells whose nuclei were stained with methyl green (Figure 4(B) and (C)). Morphometric parameters of apoptotic elements in different regions of the sturgeon myelencephalon are shown in Table 1.

In the periventricular region of the sturgeon myelincephalon, at the level of the projection of the trigeminal nerve nucleus, we found apoptotic bodies with mean diameters of $6.4 / 5.9 \mu \mathrm{m}$, which were localized among intact cells of the periventricular region. The AI values in the periventricular region of the myelencephalon were $8.9 \%$ to $9.0 \%$ (Table 1). In the subventricular zone, the total proportion of TUNEL-positive cells was smaller $(6.0 \%$; Table 1). In this zone, we found apoptotic bodies with dimensions of 7.6/6.9 $\mu \mathrm{m}$ (Table 1). In the MRF, neurons in earlier apoptotic stages were observed; TUNEL-labeled chromatin was fragmented and looked like small granules. These cells were gathered in small groups (Figure 4(C)). The AI values in the isthmus region of the reticular formation at the level of the trigeminal nerve and in cells of the interfascicular region differed insignificantly from each other $(8.9 \%, 10.6 \%$, and $9 \%$, respectively; Table 1). A high relative density

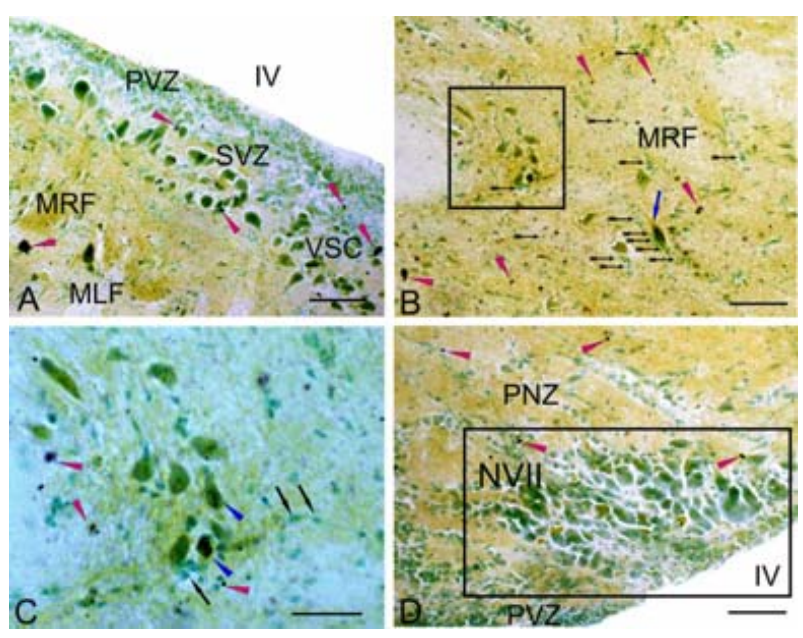

Figure 4. TUNEL-containing elements in the myelencephalon of the Amur sturgeon Acipenser schrenckii (cell nuclei are additionally stained with methyl green, by Brasher). (A) Cross section through the viscerosensory column of neurons; red triangle arrows indicate apoptotic bodies; (B) Longitudinal section at the level of the reticular formation; neurons of the reticular formation, which contain fragmented TUNEL-labeled chromatin (shown by blue arrow) and are surrounded by glial cells (shown by small figured arrows); (C) Fragment containing neurons with TUNEL-labeled fragments of DNA (shown by triangle blue arrows) is outlined by a square in B and are surrounded by glial cells (shown by black arrows); (D) Longitudinal section at the level of the facial nerve (outlined by a rectangle). VSC-viscerosensory column, and MLF-medial longitudinal fascicle. Other designations are the same as in Figure 1. Scale: (A), (B), (D) $-100 \mu \mathrm{m},(\mathrm{C})-50 \mu \mathrm{m}$. 
of glial cells has significant impact on the total AI values within the sturgeon myelencephalon. Results of measurements of morphometric indices of apoptotic bodies showed that a significant number of cases where we identified apoptosis in the brainstem MRF and isthmus zone belong just to the glial cells. In the region of the nuclei of the $\mathrm{V}$ nerve, we found heterogeneous TUNELpositive elements. Among such elements, we verified neurons with fragmented chromatin and apoptotic bodies of different sizes (Table 1). In this zone, the relative number of these elements (AI) was $12.7 \%$, while the AI in the perinuclear zone was $10.6 \%$ (Figure 2(A)). In the projection of the nucleus of the VII nerve, the number of TUNEL-positive elements was smaller (Figure 4(D)). In this zone, the AI was $5.6 \%$ vs $6.7 \%$ in the perinuclear zone (Figure 2(A)). At the level of the trigeminal nerve outlet, we observed in the MRF TUNEL-labeled midsized neurons, apoptotic bodies similar to those observed in the isthmus region, and also an additional type of small dense bodies absent in the isthmus region (Table 1). In the interfascicular region, the parameters of TUNEL-positive elements corresponded, in general, to those observed in the isthmus region. Therefore, in the reticular formation of the sturgeon brain, a population of TUNEL-positive elements demonstrated noticeable morphological heterogeneity that probably correlated with the functional one. In the visceral motor column, we found TUNEL-positive structures localized between the motoneurons (Figure 4(A)). Labeled chromatin was localized in small neurons and also in glial cells; groups of apoptotic bodies (final stage of cell degradation) were frequently observed. In this region of the myelencephalon, the AI was 3.4\% (Table 1).

In the cerebellum, TUNEL-positive elements were found in the molecular, granular, and ganglionary layers (Figure 5(A)). The pattern of apoptotic manifestations in different parts of the cerebellar body is shown in Figure 6. In the dorsal, central, and lateral regions of the cerebellar body, the number of apoptotic elements was appreciably different in the above layers. The maximum number of TUNEL-labeled cells was found in the molecular layer of the dorsal part of the cerebellar body (Figures 5(A) and 6). In the molecular layer, we observed morphologically heterogeneous labeled structures of two types, small $(6.7 / 5.3 \mu \mathrm{m})$ and larger $(9.9 / 7.0 \mu \mathrm{m}$; Table 1). The AI for the cells of the dorsal region of the molecular layer was $18 \%$. In the lateral part, the relative number of cells with apoptotic manifestations was smaller (AI 12\%), while in the central part we detected the minimum number of such elements (AI 7.5\%). In the ganglionary layer of the central and lateral parts of the cerebellar body, we found TUNEL-labeled structures whose sizes were 12.5/10.2 $\mu \mathrm{m}$ (Table 1). The AI values for cells of the ganglionary layer of the central and lateral parts were $14 \%$ and $4 \%$, respectively (Figure 6). In the dorsal part of the cerebellar body, TUNEL-labeled elements in the ganglionary layer were absent. According to the characteristics of TUNEL-positive elements,
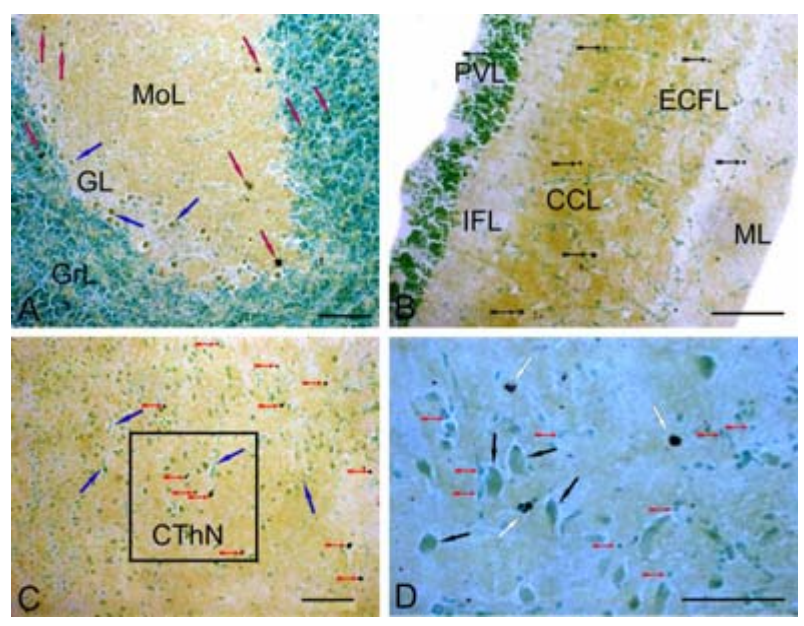

Figure 5. TUNEL-labeled elements in the cerebellum, tectum and thalamus of the Amur sturgeon Acipenser schrenckii brain. (A) Longitudinal section through the central part of the cerebellar body; red arrows indicate TUNEL-positive structures in different layers of the body, blue arrows-the Purkinje cells; (B) Section through the medial zone of the tectum; apoptotic bodies shown by figured arrows; (C) Horizontal section through the central thalamic nucleus $(\mathrm{CThN})$, delineated by rectangle, containing apoptotic elements, shown by red figured arrows, the vessels shown by blue figured arrows; (D) Apoptotic bodies (compact or irregular-shaped grained; shown by white arrows) localized among gliocytes and neurons (shown by small red figured and black arrows, respectively) in the central thalamic nucleus. Other designations are the same as in Figure 1. Scale: (A), (B), (D) $-100 \mu \mathrm{m},(\mathrm{C})-50 \mu \mathrm{m}$.

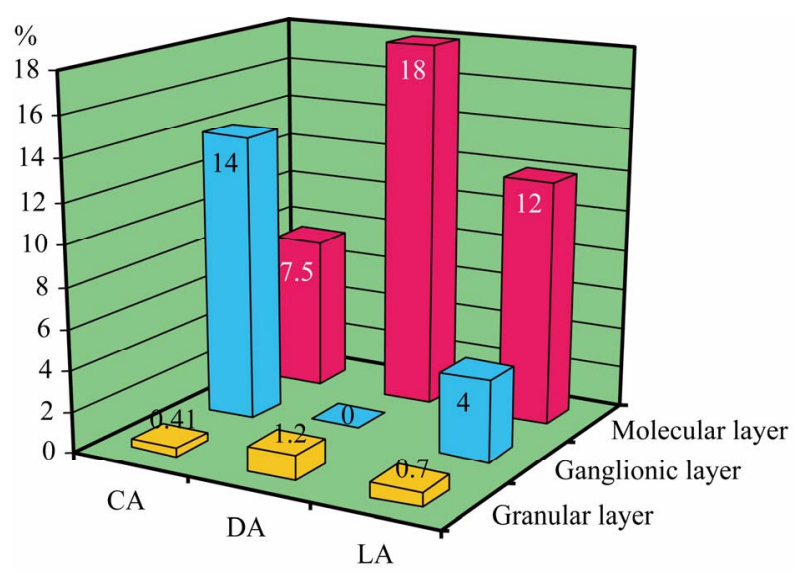

Figure 6. Intensity of the apoptotic process in different regions of the cerebellar body of the Amur sturgeon. Vertical scaleApoptosis index (AI), \%. CR, DR, and LR-Central, dorsal, and lateral regions of the cerebellar body. Yellow, blue, and pink columns correspond to the values of the AI in the granular, ganglionary, and molecular cerebellar layers, respectively. 
the granular layer was characterized by maximum morphological heterogeneity; among such elements, we classified four main types (Table 1). Another peculiarity of the granular layer of the sturgeon cerebellum was the rather high density of cells localized in this layer. This was noticeably reflected on the AI values for this region; in its dorsal, central, and lateral parts, the A. Is were $1.2 \%, 0.45 \%$, and $0.7 \%$, respectively (Figure 6).

In the tectum, TUNEL-labeled structures were observed in all layers (Figure 5(B)). Among such elements, apoptotic bodies $(6.0 / 4.7 \mu \mathrm{m})$ localized in the CCL and ECFL were most frequently observed (Table 1). Smaller bodies $(3.6 / 2.3 \mu \mathrm{m})$ were found in the inner fibrous layer (IFL) and ECFL, while comparatively large labeled elements $(8.0 / 7.1 \mu \mathrm{m})$ were identified in the CCL and ECFL. In the PL, the concentration of TUNEL-positive structures was low (AI was equal to $2 \%$ ). In contrast, we found the maximum number of apoptotic structures in the IFL; in this layer, the AI reached its maximum (20\%). In the CCL and ECFL, the number of apoptotic elements was moderate; the AI values were $8 \%$ and $9 \%$, respectively (Table 1). In the OL, the number of TUNELpositive elements was the lowest (AI was $1.5 \%$ ), while in the ML we observed $15.0 \%$ of cells with manifestations of apoptosis (Table 1).

In the thalamus, we identified four types of TUNELpositive structures (Figure 5(C)). Smaller elements $(6.4 / 5.6 \mu \mathrm{m})$ were observed in the subventricular region and lateral thalamus. These elements were, probably, products of apoptotic degeneration of glial cells. Larger sites $(8.5 / 6.5 \mu \mathrm{m})$ were found in the dorsal thalamic zones at a distance from the periventricular region. In the region of the central thalamic nuclei, the largest (11/7.9 and 13.4/8.4 $\mu \mathrm{m}$ ) TUNEL-labeled apoptotic bodies (compact or irregular-shaped grained ones) were present (Figure 5(C)). It is obvious that such bodies are indicative of the late stages of apoptotic degradation of cells in the central thalamic nuclei (Figure 5(D)). In the lateral thalamus, we observed large cell conglomerates with apoptotic manifestations (diameter 31.5/25.8 $\mu \mathrm{m}$ ) together with single apoptotic bodies. The AI in the sturgeon thalamus was $7.6 \%$.

In the hypothalamus, small TUNEL-positive apoptotic bodies $(6.3 / 5.9 \mu \mathrm{m})$ were present in the periventricular and subventricular regions. In periventricular, subventricular, and lateral hypothalamus, the AI values were, respectively, $3 \%, 6 \%$, and $18 \%$. Larger elements $(8.6 / 6.5$ $\mu \mathrm{m})$ were localized in deep layers of the lateral and ventral thalamus. The sturgeon hypothalamus was characterized by a very low density of glial cells compared with that in the thalamus and brainstem. In the lateral hypothalamus, we found TUNEL-positive conglomerates consisting of several cells (dimensions of these structures are shown in Table 1), which were localized near the exter- nal surface.

\subsection{Immunolocalisation nNOS}

In the sturgeon myelencephalon nNOS-labeled elements were indentified in the periventricular and subventricular areas, deep brain areas and cells, which are located near the external brain surface, adjoining to the brain mater as well as to heterogeneous neuron population of medial and median reticular formation, glial cells and neurons of somatovisceral medullar column (Figures 7(A)-(D)). In periventricular area the heterogeneous populations of nNOS-ip cells are arranged on a border with IV ventricle, forming a laminated layer (Figure 7(A)). In subventricular area the number of nNOS-ip cells much less, but they are presented by morphologically heterogeneous population (Figure 7(A), Table 1). The majority of the somatovisceral medullar neurons express nNOS too, while immunopositivity was revealed in large multipolar cells (obviously motoneurons) as well as in not so large neurons (Figure 7(A)). In deep layers of medulla the nNOSip cells were revealed in a content of median and medial reticular formation (Figures 7(B) and (C)). The distribution density of small nNOS-ip cells in brainstem was sufficiently big, but the number of large reticulospinal neurons was comparatively little. Near the brain external surface, bordering with the brain membranes and adjoining areas, the heterogeneous nNOS-ip cells owing high enzyme activity level were revealed (Figure 7(D)).

In cerebellum the nNOS-immunopositivity was revealed in the cells of molecular, granular and ganglionic layers (Figure 7(E)). In molecular layer the small intensively nNOS-labeled cells of two types were revealed (Table 1), which were located solely or in small groups (Figure 7(E)). In ganglionic layer two types of nNOS-ip cells, the oval 14/11 and spindle-shaped $17 / 9$ (Figure 7(E)), forming the Purkinje's cells and eurydendroid cells population, accordingly, were revealed. In granular layer a vast majority of nNOS-ip cells was presented by small round and oval neurons, sizing 7/6 (Figure 7(E), Table 1).

In tectum nNOS-ip cells in all layers, except optical one, were revealed (Figure 7(F)). In marginal layer the fibers and two types of cells, the small $6 / 6$ and bigger $8 / 6$, were intensively labeled (Table 1, Figure 7(F)). In ECFL nNOS was demonstrated in three types of large cells (Table 1, Figure 7(F)). In CCL two types of nNOS-ip cells, spindle-shaped and oval, were detected (Figure 7(E)). In PL and IFL two types of small moderately labeled nNOS-ip cells were determined (Table 1, Figure 7(F)).

In thalamus nNOS-ip cells in periventricular and subventricular areas were verified (Table 1). In periventricular area large number of elongated highly immunopositive 


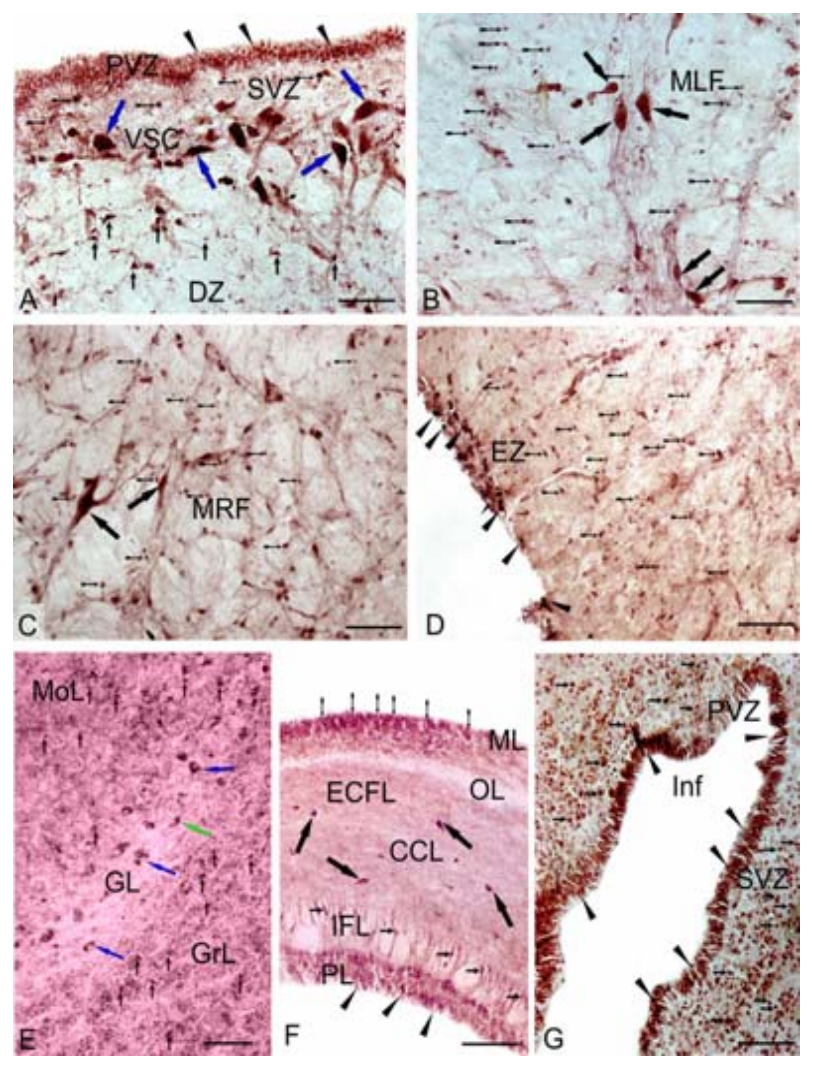

Figure 7. Immunolocalisation neuronal nitric oxide synthase (nNOS) in the brain of Amur sturgeon Acipenser schrenckii. (A) Cross section of dorsal parts of the myelencephalon, triangular black arrows indicate nNOS-ip cells in the periventricular zone, blue arrows indicate ip neurons in the somatovisceral column; black vertical arrows indicate small ip cells of deep area; (B) Immunopositive neurons (shown by black arrows) in the median and medial in (C) reticular formation, (D) Fragment of the myelencephalon external zone adjacent to the cerebral covers; (E) Cross section through the central part of the cerebellar body; black vertical arrows indicate nNOS-positive structures in molecular and granular layers of the body, blue arrows-the Purkinje cells, green arrow-eurydendroid neuron; (F) Cross section through the medial part of the optic tectum; arrows indicate nNOS-positive cells in different layers; (G) Horizontal section through the hypothalamus. Other designations are the same as in Figures 1 and 4. Scale: (A)-(D), (F), (G)-100 $\mu \mathrm{m}$, (E) $-50 \mu \mathrm{m}$.

cells was founded. In dorsal thalamic area the oval and elongated nNOS-ip cells were revealed (Table 1). In periventricular area of hypothalamus the number of nNOS-ip cells was very high (Figure $7(\mathbf{G})$ ), the most of them have had spindle-shaped form and they were organized as neuroepithelium. In subventricular area immunopositive cells were not so numerous and have represented two types of cells (Table 1). In deep layers of lateral and ventral hypothalamus the number of nNOS-ip cells was reduced, but the labeled cells were bigger in comparison with those in periventricular and subventricular areas (Figure 7(G)).

\section{DISCUSSION}

The results of experimental and morphological investigations on teleost fishes have shown, that in the CNS neurons NO is participating in different functional mechanisms, connected with regeneration [13], differentiation $[14,15]$, cluster communications between neurons and glial cells [16], neuromorphogenesis [13,17], neurotransmission and cell metabolism [18]. The results of immunohistochemical and morphometric analysis of the nNOS-, PCNA and TUNEL-positive elements in threeyears-old sturgeon brain have shown the availability of large amount of immunopositive cells, but ratio between proliferation and apoptosis in the different sturgeon brain parts were differed substantially, what may be connected with unequal rate of growth and differentiation of the different brain regions.

Taking into account the known fact, that proliferative processes in matrix brain areas are not restricted by embryonic period, but continue during postembryonic stages of development; the special role in these procesess is given in low vertebrates, especially in teleost fishes, to nitric oxide [20,21]. In the brain of adult zebrafish, nNOS mRNA-expressing populations are closely associated with the proliferation zones [22], that generate new cells throughout life [23]. The results of present study demonstrate the nNOS presence in periventricular areas, which contain ependymal cells, subventricular area, deep brain layers and also external zone, adjoining to the brain coat in adult specimen of sturgeon. In the same brain areas the PCNA-ip and TUNEL-labeled structures were identified, what witness the NO participation both in processes postembryonic cells proliferation and in apoptosis. One proposed mechanism for the effects of NO in developmental processes is a suppressive influence on DNA synthesis, whereby NO acts a negative regulator on precursor cells and thereby affects the balance of cell proliferation, differentiation and apoptosis [13,24]. In mammals, the presence of NO-producing sustems and NO-mediated action in developmental processes of the CNS have preferentially been studied during early postnatal stages [25]. It has been shown, that in early postnatal period the development continue in ependymal cells of third ventricle in rats [14], central canal of spinal cord in mouse [26], and in lateral ventricle in rabbit [27]. The main sources of NO-mediated reactions, including those in neurogenesis and neuronal plasticity, are nNOS or similar isoforms of enzyme in different species [24,25], including in restricted brain areas with ongoing neurogenesis and neuronal plasticity in adult mammals [28, 29]. The involvement of NO in postnatal neurogenesis was found in different vertebrates [30]. In lower vertebrates such as teleosts, NO has been emphasized to play a versatile role in the developmental of the CNS during 
both embryonic and post-embrionic life stages [20,21]. Two main neurogenesis sites have been identified in the adult mammalian brain. They include the subventricular zone (SVZ), and the subgranular zone (SGZ) of dentate gyrus (DG). The process of neurogenesis is composed of following main steps, which include precursor proliferation, migration; differentiation, integration and survival. It has been demonstrated, that SVZ of mammals is surrounded by nNOS positive neurons [31] and cells expressing nNOS, also have been identified in neuronal precursors in DG [28]. These findings suggest nNOS might take part in neurogenesis regulation. In morphological study on mammals the adult mouse brain have been shown, that nitric oxide (NO), a signaling molecule in the nervous system with a role in embryonic neurogenesis, may be produced in the proximity of the progenitor cells in the adult brain, as a prerequisite to proposing a functional role for $\mathrm{NO}$ in adult neurogenesis [29]. Proliferating and immature precursor cells were identified by immunohistochemistry for bromodeoxyuridine (BrdU) and nitrergic neurons by either NADPHdiaphorase staining or immunohistochemical detection of neuronal NO synthase. Nitrergic neurons with long varicose processes were found in the SVZ, intermingled with chains of cells containing BrdU. Within the olfactory bulb, many small cells in the granular layer and around the glomeruli expressed either BrdU or nNOS and, in some cases, both markers [29]. Colocalization was also found in a few isolated cells at a certain distance from the neurogenesis areas. The anatomical disposition shown indicates that NO may be released close enough to the neuronal progenitors to allow a functional influence of this messenger in adult neurogenesis.

The participation of nitric oxide in the postembryonal proliferation process in different brain areas of sturgeon confirm the results of correlation analysis of the nNOSand PCNA-ip cells parameters in periventricular, subventricular and deep medullar areas (Table 2). It has been shown, that correlation coefficients (CC) between parameters of nNOS- and PCNA-ip cells in periventricular area constitute 0.9 ; in subventricular area -0.8 ; and in deep medullar layers 0.9 (in Table 2, the CC values are shown by bold letters). The analysis of the data obtained for this cerebral structure shows the presence of relationships between NO-ergic and proliferative cells. In present time it is established, that in vertebrates NO constitutes a signal molecule acting not only during embryonic neurogenesis, but in postembryonic period too [29]. The results of our investigation confirm this resume and allow to suggest the nNOS participation in postembryonic morphogenesis of the sturgeon brain.

Studies in mammals have shown that during embryonic development apoptosis leads to elimination of young cells, which, after arrival at the target site, have failed to make proper connections with other neurons and to receive adequate amounts of specific survival factors produced by cells in the target area [1]. Although not yet examined in the context of adult neurogenesis, it is possible that a similar mechanism regulates the number of cells born in the adult brain. The investigations of cellular and molecular mechanisms of apoptosis have shown that these processes are caused by the free radicals accumulation, especially of the NO-metabolites. They caused the glutamate exitotoxicity development, which, in turn, leads to oxidative stress [12,32]. The results of the nNOS immunolocalisation investigation have shown that, NO-producing systems include the morphologically and functionally heterogeneous neurons and glial cells. Our data are in accordance with results in different teleost species: Oreochromis niloticus [9], goldfish $[6,7]$ and Danio rerio [22]. It has been shown, that NO in normal conditions in the teleost fishes brain is present in various types of neurons [5,8-10], as well as in astrocytes and endotheliocytes [7], oligodendrocytes [11], and tanicytes [12], which are widespread practically in all areas of brain and spinal cord. It is known, that excessive NO production in the neuron cytoplasm stimulates the local formation of superoxide ions, which form the first component of cytotoxic effect [33]. The zone of superoxide anion toxicity is determined by the diffusion constant in the brain tissue. NO has been shown [34] to be able to diffuse to some $130 \mu \mathrm{m}$, what exceeds considerably the average size of cellular somata, but quite conform for the intercellular transmission. This may bring to formation of peroxynitrite in adjacent cells. Toxic oxidants disturb the connections between components of cell membranes and cytoplasmic proteins, triggering the mechanisms of apoptosis [35]. The molecular properties of NO prevent it from being deposited in organelles and synaptic terminals, though it serves ideal condition for spatial signaling between neurons [24]. The results of our investigation demonstrate, that NO-ergic production in the brain cells of sturgeon is sufficiently high, so NO may easily penetrate through nuclear membrane and influence autocrinically a genetic apparatus of neuboring neurons and glial cells, causing their mass mortality. This confirms the results of immunolocalisation TUNEL- and nNOS-ip cells in different parts of sturgeon brain. NO is capable to diffuse on substantial distances, securing the mechanisms of apoptotic death in whole conglomerates of neuronal cells, which we revealed in sturgeon in thalamus, cerebellum and lateral hypothalamus. High coefficients in apoptotic and NO-ergic elements were shown in investigation of TUNEL-labeled and nNOS-ip cells in different brain areas. Thus, in the isthmus area $\mathrm{CC}$ have constituted 0.8 ; in central thalamic nucleus -0.8 ; caudal brain stem area- 0.9 ; (in Table $3 \mathrm{CC}$ values are shown by bold letters). This allow to suggest the NO 
Table 2. Correlation coefficients for relations between PCNA and nNOS-ip parameters of neurons in medulla oblongata of the Amur sturgeon Acipenser schrenckii.

\begin{tabular}{|c|c|c|c|c|c|c|c|c|c|c|c|c|}
\hline & $\begin{array}{c}\mathrm{PVZ} \\
(\mathrm{NO}) \mathrm{a}\end{array}$ & $\begin{array}{c}\text { PVZ } \\
\text { (NO)б }\end{array}$ & $\begin{array}{c}\text { PVZ } \\
\text { (PCNA)a }\end{array}$ & $\begin{array}{c}\text { PVZ } \\
\text { (PCNA)б }\end{array}$ & $\begin{array}{c}\text { SVZ } \\
\text { (NO)a }\end{array}$ & $\begin{array}{c}\text { SVZ } \\
\text { (NO)б }\end{array}$ & $\begin{array}{c}\text { SVZ } \\
\text { (PCNA)a }\end{array}$ & $\begin{array}{c}\mathrm{SVZ} \\
\text { (PCNA)б }\end{array}$ & $\begin{array}{c}\mathrm{DZ} \\
(\mathrm{NO}) \mathrm{a}\end{array}$ & $\begin{array}{c}\mathrm{DZ} \\
\text { (NO)б }\end{array}$ & $\begin{array}{c}\mathrm{DZ} \\
\text { (PCNA)a }\end{array}$ & $\begin{array}{c}\mathrm{DZ} \\
\text { (PCNA)б }\end{array}$ \\
\hline $\begin{array}{c}\mathrm{PVZ} \\
(\mathrm{NO}) \mathrm{a}\end{array}$ & 1 & & & & & & & & & & & \\
\hline $\begin{array}{c}\mathrm{PVZ} \\
(\mathrm{NO}) \mathrm{b}\end{array}$ & -0.02 & 1 & & & & & & & & & & \\
\hline $\begin{array}{c}\text { PVZ } \\
\text { (PCNA)a }\end{array}$ & 0.92 & -0.21 & 1 & & & & & & & & & \\
\hline $\begin{array}{c}\text { PVZ } \\
\text { (PCNA)b }\end{array}$ & -0.06 & -0.30 & -0.003 & 1 & & & & & & & & \\
\hline $\begin{array}{c}\text { SVZ } \\
(\mathrm{NO}) \mathrm{a}\end{array}$ & 0.95 & -0.27 & 0.94 & 0.08 & 1 & & & & & & & \\
\hline $\begin{array}{c}\text { SVZ } \\
(\mathrm{NO}) \mathrm{b}\end{array}$ & 0.48 & 0.11 & 0.37 & -0.01 & 0.43 & 1 & & & & & & \\
\hline $\begin{array}{c}\text { SVZ } \\
\text { (PCNA)a }\end{array}$ & 0.86 & -0.10 & 0.90 & 0.17 & 0.89 & 0.21 & 1 & & & & & \\
\hline $\begin{array}{c}\mathrm{SVZ} \\
\text { (PCNA)b }\end{array}$ & 0.31 & 0.11 & 0.47 & -0.05 & 0.29 & -0.34 & 0.65 & 1 & & & & \\
\hline $\begin{array}{c}\mathrm{DZ} \\
(\mathrm{NO}) \mathrm{a}\end{array}$ & 0.91 & -0.18 & 0.93 & 0.16 & 0.93 & 0.61 & 0.86 & 0.31 & 1 & & & \\
\hline $\begin{array}{c}\mathrm{DZ} \\
(\mathrm{NO}) \mathrm{b}\end{array}$ & 0.34 & 0.01 & 0.49 & 0.25 & 0.31 & 0.26 & 0.29 & 0.15 & 0.48 & 1 & & \\
\hline $\begin{array}{c}\mathrm{DZ} \\
\text { (PCNA)a }\end{array}$ & 0.96 & -0.06 & 0.93 & -0.01 & 0.96 & 0.53 & 0.88 & 0.32 & 0.93 & 0.31 & 1 & \\
\hline $\begin{array}{c}\mathrm{DZ} \\
\text { (PCNA)b }\end{array}$ & 0.68 & 0.15 & 0.54 & 0.23 & 0.67 & 0.68 & 0.67 & 0.13 & 0.73 & -0.01 & 0.76 & 1 \\
\hline
\end{tabular}

Footnotes: Meaningful correlation coefficients values are shown by bold letters, explanation see text. Designations: PVZ-periventricular; SVZ-subventricular; DZ-deep zone of medulla oblongata, a and b-maximum length (large diametr) and maximum width (small diametr) of the cell cection.

Table 3. Correlation coefficients for relations between TUNEL-labeled and nNOS-ip parameters of neurons in the isthmus, central thalamic nuclei and caudal part of medulla oblongata of the Amur sturgeon Acipenser schrenckii.

\begin{tabular}{ccccccc}
\hline & IA (TUNEL) & IA (NO) & CTN (TUNEL) & CTN (NO) & CMO (TUNEL) & CMO (NO) \\
\hline IA (TUNEL) & 1 & & & & \\
IA (NO) & $\mathbf{0 . 8 7}$ & 1 & & & \\
CTN (TUNEL) & 0.77 & 0.76 & 1 & & & \\
CTN (NO) & 0.57 & 0.66 & $\mathbf{0 . 8 0}$ & 0.50 & 1 & 1 \\
CMO (TUNEL) & 0.65 & 0.85 & 0.77 & 0.52 & $\mathbf{0 . 9 5}$ & 1 \\
CMO (NO) & 0.81 & 0.71 & 0.90 & & \\
\hline
\end{tabular}

Footnotes: Meaningful correlation coefficients values are shown by bold letters, explanation see text. Designations: IA-isthmus area, CTN-central thalamic nucleus, CMO-caudal part of medulla oblongata.

participation in the cell death control in postnatal ontogenesis in the amur sturgeon brain.

Thereby, the results of investigation show, that in the sturgeon brain NO may act as a cytotoxic proapoptogenic factor, as well as a factor stimulating proliferation.
Cytotoxic and neuroprotective effects may regarded as interconnected elements of one action. Supposing, that redundant NO formation potentiate apoptosis mechanisms in the zones of postmitotic neuroblasts localization, but the factors, which decrease NO production, may be 
regarded as compensatory. NO, which has proapoptotic actions, is actively involved in the mechanisms of neurogenesis. Taken together, these findings suggest that apoptosis is used as a mechanism which regulates the number of young cells after they have reached their target areas. A similar observation has been made in the teleostean retina during postembryonic development. Apoptotic cell death occurs predominantly in areas where the new cells differentiate and become integrated into visual circuits [36].

\subsection{Proliferation and Apoptosis in Postembrionic Ontogenesis of Sturgeon}

According to the modern concept, cell proliferation, cell differentiation, and apoptosis in the fish brain within the postembryonic period and also in adult individuals should be considered an integral set of interrelated functional phenomena [37]. The development of "newborn" cells in the adult brain of teleost fishes is characterized by a few specificities, either remain near the region where they developed or can migrate (during 1 to 2 weeks from the moment of their formation) from the proliferation zone (where they were formed) to the specific target regions [38]. In young (2-month-old) sturgeons, active proliferation of the cells was observed in the periventricular regions of the telencephalic, preoptic, and thalamic brain subdivisions [38]. Within this stage of development, an extremely high proliferation potential in the sturgeon brain also results from the formation of secondary foci of cell proliferation (secondary matrix zones of the brain). In 3-ears-old sturgeons, a high proliferative activity is preserved in the periventricular zone of different cerebral subdivisions, and the intensity of proliferation significantly exceeds that of apoptosis. These phenomena are more expressed in the caudal divisions of the myelencephalon; this fact allows us to consider this region as the main center of postembryonic neurogenesis. In contrast, the number of cells subjected to apoptosis either exceeds the number of proliferating units (in the myelencephalon) or is nearly equal to the above index (in the hypothalamus and thalamus) in the subventricular zone of the sturgeon brain. Studies carried out on fishes, e.g., on Apteronotus, showed that about $50 \%$ of "adult-born" brain cells are eliminated according to the apoptotic scenario during several weeks from the moment of their formation and migration to deep cerebral layers [39]. The remaining $50 \%$ of the cells can remain in a resting state during the entire period of life of the fish or can differentiate into neurons or gliocytes [39]. In deep layers of the sturgeon myelencephalon, we have found small PCNA-ip cells, which were probably gliocytes.

In contrast, the distribution of apoptotic and NO-ergic elements was observed in functionally heterogeneous cell populations (neurons of the reticular formation, nuclei of the craniocerebral nerves, and perinuclear regions of V, VII, and X nerves), as well as in gliocytes. Such distribution of apoptotic phenomena in adult fishes is typical for the postmitotic differentiating cerebral zones [2]. The presence of NO in V, VII, X craniocerebral nuclei and adjoining reticular formation, earlier was revealed in other species of adult teleost fishes [5,7-10,40], but the presence of NO-producing elements in the somato- and viscerosensor medullar areas may mean, that in these areas NO is acting as apoptogenic factor, which induces cellular death in areas of the postmitotic neuroblasts localization and render the controlling effect on development and differentiation of chemosensory areas in postembryonic development. We consider the presence of highly immunoreactive cells in the external (adjacent to brain coats) layers a special feature of the above-mentioned age period. Such PCNA- and nNOSlabeled cells were found in the myelencephalon, cerebellum, and tectum. Our data agree with observations made on other fish species within the period of postnatal ontogenesis $[1,2]$. Recent studies on fishes demonstrated that numerous centers of proliferation are localized along the entire rostro-caudal axis of the brain. However, the patterns of postnatal proliferation were investigated in detail only in three fish species, namely in the stickleback (Gasterosteus aculeatus, Perciformes), a gymnotiform electric fish (knifefish), Apteronotus leptorhynchus, and a cyprinid fish, danio (Danio rerio) [37].

In the sturgeon cerebellum, a considerable proliferative potential was found in the cells localized in the molecular layer. Alongside with intense proliferation in this layer, we also observed here clearly pronounced apoptosis. Investigation of nNOS immunolocalisation have shown, that in molecular and granular layers in sturgeon brain the nNOS-ip cells are presented by morphologically homogeneous type of neurons, morphometric characteristic of which are in accordance with such of apoptotic bodies, revealed in the same zones. Thus, we may prognosticate, that NO in sturgeon cerebellum serve as proapoptogenic factor, regulating death of postmitotical cells of molecular and granular layers in sturgeon. The NO-ergic activity identification in projection neurons of ganglionic cerebellum layer in Purkinje and eurydendroid cells confirm the data on other species of fishes [5, $6,41]$. Nitric oxide, synthesized in Purkinje cells and in somas of eurydendroid neurons, may act as a volume neurotransmitter to the significant distance in the cerebellum, by extracerebellar projections forming, which arise from eurydendroid neurons [42]. The presence of TUNEL-positive elements, corresponding parameters of gandlionic cells, confirm the participation of $\mathrm{NO}$ as a factor, regulating quantity of Purkinje cells and euryden- 
droid neurons in postnatal development.

\subsection{The Sensory System Development}

In contrast to mammals in which central divisions of sensory systems are completely formed and correspond strictly to the number of sensory receptors at the moment of birth and/or immediately after this event, sensory projections in the fish brain continue their growth and development during the entire life. Such a peculiarity of the fishes is related to the fact that the CNS organization must adapt to a significant permanent increase in the size of the body and, correspondingly, to a rise in the volume of incoming sensory information. Identification of nNOS in projections areas of the somato- and viscerosensory nuclei of the myelencephalon and tectum opticum of the sturgeon confirmed the hypothesis about participation NO in controlling of postnatal development of sensory systems. Our findings agree with the published data on intensification of differential growth in primary sensory regions in the lobe of the nucl. vagus of the carp, as well as in the Danio retina and tectum, compared with other cerebral regions $[43,44]$. In the retina and tectum of birds and reptiles, the intensity of neurogenesis decreases significantly within the postembryonic period, up to complete cessation of this process [45]. Up to now, it remains unknown whether all types of neurons develop and are integrated into the corresponding networks of the growing brain of fishes. It seems probable that some initial level of organization of neuronal networks in fishes is already pre-formed at the moment of their hatching, and only some types of neurons continue their formation and integration into existing networks during the later period of life.

It is believed that the weak ability for substitution or development of new neurons in the mammalian brain is related to the limited ability of such cells in animals of this class to be integrated into mature neuronal networks [46]. It is hypothesized that neurons formed de novo in adult animals are distinguished by a higher plasticity compared with that of preexisting cells $[47,48]$. This viewpoint agrees well with our findings on the sturgeon and allows us to suppose that postembryonic neurogenesis correlates with coordinated growth of the sensory systems and sensory structures of the brain. Therefore, this phenomenon can open possibilities for the processing of new ontogenetic experience. The intensity of proliferative activity of cells in the medial zone of the tectum opticum of the sturgeon brain exceeds that in the lateral zone. This allows us to hypothesize that the growth of the tectum is asymmetric; this structure is enlarged mostly at the expense of the medial zone. In contrast to the activity of PCNA within early postnatal development stages, the maximum respective activity in the tectum of 3-year-old sturgeons is observed in the ML. In this part, in contrast to the myelencephalon and cerebellum, we found cell populations with PCNA-, TUNEL and NO-production. This findings allow us to suppose the presence of NO-dependent mechanism of regulation in tectum opticum postnatal morphogenesis. Proliferating cells were also observed in deep layers of the tectum, and the intensities of proliferation in such layers of the medial and lateral zones differed from each other significantly. The maximum concentration of apoptotic elements was observed within the IFL corresponding to the zone of localization of postmitotic neuroblasts, which left the proliferative cycle in the PVL.

In the sturgeon myelencephalon, the chemosensory region corresponding to projections of the facial and vagus nerves was characterized by increased proliferative activity; the intensity of the latter exceeded the level of apoptosis in these regions. High values of the AI in the perinuclear regions of the trigeminal, facial, and vagus nerves in the sturgeon brainstem allow us to consider these zones as postmitotic differentiating regions typical of late stages of neurogenesis. Such a conclusion agrees with the data obtained on the Apteronotus [37]. It is likely that excessive neuroblasts formed in the periventricular zone and migrating to the zones of differentiation are eliminated in these regions of the sturgeon brain according to the apoptosis scenario. Incorporation of new cells into the neuronal networks existing earlier in the sensory regions is directly related, first of all, to an increase in the size of the brain in the course of growth of the fish. However, it should be taken into account that fishes, immediately after hatching, possess relatively well preformed sensory and motor systems making possible rather rapid training for complex behavioral habits, e.g., active catching of food and avoidance of predators. This indicates that some parts of the CNS of fishes, which are responsible for information processing and realization of functional needs of the organism necessary within a certain life period, begin to function before hatching. The later postembryonic growth can be considered a process of delayed development related to the maintenance of the functions necessary in future, e.g., for the formation of zoosocial communication or sexual behavior. Therefore, our conclusion that some parts of the sturgeon brain remain, in fact, in the neotenic state over a rather long postembryonic period seems to be quite logical. This hypothesis explains high indices of proliferative activity in some brain regions in cartilaginous ganoid fishes.

\section{CONCLUSIONS}

Therefore, our findings allow us to conclude that the processes of proliferation and apoptosis in the brain of 
3-year-old sturgeons remain rather intense, and the ratios between these processes in different brain structures are rather dissimilar.

Nitric oxide in the Amur sturgeon brain may play a role of cytotoxic proapoptogenic factor and a factor, which stimulate cell proliferation. The availability of NO-producting elements in somato- and viscerosensory medullar areas, tectum, cerebellum, thalamus and hypothalamus of Amur sturgeon permits to suppose that in these areas NO constitutes a proapoptogenic factor, inducing the programmed cell death, occurring in the areas of the postmitotic neuroblasts localization, causing regulating impact on development and differentiation of chemosensory, visual, motor and hypophysotrophic brain areas in postnatal development. The maximal proliferation activity and high concentration of NO-ergic cells were revealed in external layers, adjacent to the subpial medullar, cerebellar and tectal zones, what allows to suppose participation of NO in postembryonic neurogenesis in these brain structures as a factor, which regulate cells proliferation. The highest concentration of proliferating cells was revealed in the medullar periventricular area, that allows to regard this area as a major brain region of postembryonic neurogenesis. The different ratios between proliferation and the programmed cell death indices were revealed in sensor brain centers: tectum and projections of V, VII and X cranial nuclei, witnessing the presence of different growth and differentiation speed, taking place in visual and chemosensory centers of the Amur sturgeon brain.

\section{ETHICAL APPROVAL}

The experiments were approved by the Animal Ethics Committee of A. V. Zhirmunskii Institute of Marine Biology, Far Eastern Branch of Russian Academy of Sciences Vladivostok, Russia.

\section{AUTHOR STATEMENTS}

The manuscript is original, has not been submitted to or is not under consideration by another publication, has not been previously published in any language or any form, including electronic, and contains no disclosure of confidential information or authorship/patent application disputations.

\section{REFERENCES}

[1] Zupanc, G.K.H., Hinsch, K. and Gagr, F.H. (2005) Proliferation, migration, neuronal differentiation and longterm survival of new cells in the adult zebrafish brain. Journal of Comparative Neurology, 488, 290-319. http://onlinelibrary.wiley.com/doi:10.1002/cne.20571

[2] Grandel, H., Kaslin, J., Ganz, J., Wenzel, I. and Brand, M. (2006) Neural stem cells and neurogenesis in the adult zebrafish brain: Origin, proliferation dynamics, migration and cell fate. Developmental Biology, 295, 263-277. doi:10.1016/j.ydbio.2006.03.040

[3] Soutschek, J. and Zupanc, G.K.H. (1996) Apoptosis in the cerebellum of adult teleost fish, Apteronotus leptorhynchus. Developmental Brain Research, 97, 279-286. doi:10.1016/j.ydbio.2006.03.040

[4] Ampatzis, K. and Dermon, C. (2007) Sex differences in adult cell proliferation within the zebrafish (Danio rerio) cerebellum. European Journal of Neuroscience, 25, 10301040.

[5] Arevalo, R., Alonso, J.R., Garcia-Ojeda, E., Brinón, J.G., Crespo, C. and Aijón, J. (1995) NADPH-diaphorase in the central nervous system of the tench (Tinca tinca L., 1758) The Journal of Comparative Neurology, 352, 398420.

http://onlinelibrary.wiley.com/doi/10.1002/cne.90352030 $\underline{7}$

[6] Bruning, G., Katzbach, R. and Mayer, B. (1995) Histochemical and immunocytochemical localization of nitric oxide synthase in the central nervous system of the goldfish, Carassius auratus. The Journal of Comparative Neurology, 358, 353-382.

http://onlinelibrary.wiley.com/doi/10.1002/cne.90358030 $\underline{5}$

[7] Villani, L. and Guarnieri, T. (1995) Localization of NADPH-diaphorese in the goldfish brain. Brain Research, 679, 261-266. doi:10.1016/0006-8993(95)00240-Q

[8] Virgilli, M., Poli, A., Beraudi, A., Giuliani, A. and Villani, L. (2001) Regional distribution of nitric oxide synthase and NADPH-diaphorase activities in the central nervous system of teleost. Brain Research, 901, 202-207. doi:10.1016/S0006-8993(01)02357-5

[9] Bordieri, L., Persichini, T., Venturini, G. and Cioni, C. (2003) Expression of nitric oxide synthase in the preoptic-hypothalamo-hypophyseal system of the teleost Oreochromis niloticus. Brain, Behavior and Evolution, 62, 4355.

[10] Jadhao, A.G. and Malz, C.R. (2004) Nicotinamide adenine dinucleotide phosphate (NADPH)-diaphorase activeity in the brain of a cichlid fish, with remarkable findings in the entopeduncular nucleus: A histochemical study. Journal of Chemical Neuroanatomy, 27, 75-86. doi:10.1016/j.jchemneu.2003.12.001

[11] Perez, S.E., Adrio, F., Rodriguez, M.A., Rodriguez-Moldes, I. and Anadon, R. (1996) NADPH-diaphorase histochemistry reveals oligodendrocytes in the rainbow trout (teleosts) Neuroscience Letters, 205, 83-86. doi:10.1016/0304-3940(96)12379-X

[12] Ma, P.M. (1993) Tanycytes in the sunfish brain: NADPH-diaphorase histochemistry and regional distribution. The Journal of Comparative Neurology, 336, 77-95. http://onlinelibrary.wiley.com/doi/10.1002/cne.90336010 $\underline{7}$

[13] Holmqvist, B., Ellingsen, B., Forsell, J., Zhdanova, I. and Alm, P. (2003) The early ontogeny of neuronal nitric oxide synthase systems in the zebrafish. Journal of Ex-perimental Biology, 207, 923-935.

[14] Bruni, J.E. (1998) Ependymal development, proliferation, and function. Microscopy Research and Technique, 41, $2-13$. 
http://onlinelibrary.wiley.com/doi/10.1002/\%28SICI\%29 1097-0029\%2819980401\%2941:1\%3C2::AID-JEMT2\% 3E3.0.CO;2-Z

[15] Oqura, T., Nakayama, N., Fujisawa, H. and Esumi, H. (1996) Neuronal nitric oxide synthase expression in neuronal cell differentiation. Neuroscience Letters, 204, 8992. doi:10.1016/0304-3940(96)12324-7

[16] Cuodhi, B. (2001) Glial cells: Basic components of clusters of supramedullary neurons in pufferfish. Journal of Neurocytology, 30, 503-513.

[17] Villani, L. (1999) Development of NADPH-diaphorase in the central nervous system of the cichlid fish Tilapia mariae. Brain, Behavior and Evolution, 54, 147-158.

[18] Holmqvist, B. and Ekström, P. (1997) Subcellular localization of neuronal nitric oxide synthase in the brain of a teleost: An immunoelectron and confocal microscopical study. Brain Research, 745, 67-82. doi:10.1016/S0006-8993(96)01128-6

[19] Merkulov, G.A. (1969) Course of Pathological/Histological Technique. Meditsina, Leningrad, $423 \mathrm{p}$.

[20] Fritsche, R., Schwerte, T. and Peltser, B. (2000) Nitric oxide and vascular reactivity in developing zebrafish, Danio rerio. American Journal of Physiology-Regulatory, Integrative and Comparative Physiology, 279, 22002207. http://ajpregu.physiology.org/content/279/6/R2200

[21] Devades, M., Liu, Z., Kaneda, M., Arai, K., Matsukawa, T. and Kato, S. (2001) Changes in NADPH diphorase expression in the fish visual system during optic nerve regeneration and retinal development. Neuroscience Research, 40, 359-365. doi:10.1016/S0168-0102(01)00251-6

[22] Holmqvist, B., Ellingsen, B., Alm, P., Forsell, J., Oyan, A., Goksoyr, A., Fjose, A. and Seo, H. (2000) Identification and distribution of nitric oxide synthase in the brain of adult zebrafish. Neuroscience Letters, 292, 119122. doi:10.1016/S0304-3940(00)01460-9

[23] Wulliman, M.F. and Knipp, S. (2000) Proliferation patterns changes in the zebrafish brain from embryonic through early postembryonic stages. Anatomy and Embryology, 202, 385-400. http://www.springerlink.com/content/yahxhg9tvvq64clm

[24] Puenova, N., Scheinker, V., Cline, H. and Enikolopov, G. (2001) Nitric oxide is an essential negative regulator of cell proliferation in Xenopus brain. Journal of Neurocytology, 21, 8809-8818.

[25] Mize, R.R., Dawson, T.M., Dawson, V.L. and Friedlander, M.J. (1998) Nitric oxide in brain development, plasticity and disease. Progress in Brain Research, 118, $1-302$.

[26] Sturrock, R.R. (1981) An electron microscopic study of the development of the ependyma of the central canal of the mouse spinal cord. Journal of Anatomy, 132, 119-136. http://www.ncbi.nlm.nih.gov/pmc/articles/PMC1233400

[27] Abbate, F., Laura, R., Muglia, U. and Bronzetti, P. (1993) Differentiation of ependymal surface of lateral ventricles in fetus and newborn rabbits: Observations by SEM. Anatomia, Histologia, Embryologia, 22, 348-254. http://www.ncbi.nlm.nih.gov/pubmed/8129170
[28] Islam, A.T., Kuraoka, A. and Kawabuchi, M. (2003) Morphological basis of nitric oxide production and its correlation with the polysialylated precursor cells in the dentate gyrus of the adult guinea pig hippocampus. Anatomical Science International, 78, 98-103. http://www.springerlink.com/content/q484550176361710

[29] Moreno-Lopez, B., Noval J.A., Gonzalez-Bonet L.G. and Estrada C. (2000) Morphological bases for a role of nitric oxide in adult neurogenesis. Brain Research, 869, 244-250. doi:10.1016/S0006-8993(00)02474-4

[30] Bicker, G. (2005) Stop and go with NO: Nitric oxide as regulator of cell motility in simple brains. BioEssays, 27, 495-505.

[31] Romero-Grimaldi, C., Moreno-Lypez, B. and Estrada, C. (2008) Age-dependent effect of nitric oxide on subventricular zone and olfactory bulb neural precursor proliferation. The Journal of Comparative Neurology, 506, 339-346.

[32] Kalinichenko, S.G. and Matveeva N.Yu. (2008) Morphological Characteristics of Apoptosis and Its Significance in Neurogenesis. Neuroscience and Behavioral Physiology, 38, 333-344.

[33] Reutov, V.P. (2000) Medical-biological aspects of the nitric oxide and superoxide anion radical cycles. Vestnik Rossiiskoi Akademii Meditsinskikh Nauk, 4, 35-41. http://www.ncbi.nlm.nih.gov/pubmed/10832412

[34] Beckman, J.S. (1996) The physiology and pathophysiological chemistry of nitric oxide. Nitric oxide: Principles and actions. Acafemic Pressw, San Diego, 1-82.

[35] Estvez, A.G., Spear, N. and Manuel, S.M. (1998) Nitric oxide and superoxide contribute to motor neuron apoptosis induced by trophic factor deprivation. Journal of Neurocytology, 18, 923-931. http://www.jneurosci.org/content/18/3/923

[36] Brune, B., Sandau, K. and Von Kneten A. (1998) Apoptotic cell death and nitric oxide: mechanisms of activation and antagonistic signal pathways (review). Biokhimiya, 63, 966-975. http://www.ncbi.nlm.nih.gov/pubmed/9721334

[37] Zupank, G.K.H. (2009) Towards brain repair: Insights from teleost fish. Seminars in Cell and Developmental Biology, 20, 683-690. doi:10.1016/j.semcdb.2008.12.001

[38] Pushchina, E.V., Fleishman, M.Yu. and Timoshin, S.S. (2007) Proliferative zones in the brain of the Amur sturgeon fry. Interaction with neuromeres and migration of secondary matrix zones. Russian Journal of Developmental Biology, 38, 286-293. http://www.ncbi.nlm.nih.gov/pubmed/18038653

[39] Zupank, G.K.H. (1999) Neurogenesis, cell death and regeneration in the adult gymnotiform brain. Journal of Experimental Biology, 202, 1435-1446. http://jeb.biologists.org/content/202/10/1435.long

[40] Pushchina, E.V. (2007) Nitric oxide-ergic organization of medullar cranial nuclei in teleost fishes. Tsitologiia, 49, 471-83. http://www.ncbi.nlm.nih.gov/pubmed/17802744

[41] Pushchina, E.V. and Varaksin, A.A. (2001) Argyrophilic and nitric oxidergic bipolar neurons in cerebellum of the opisthocentrus Pholidapus dybowskii. Journal of Evolu- 
tionary Biochemistry and Physiology, 37, 569-575. http://www.ncbi.nlm.nih.gov/pubmed/11771249

[42] Ikenaga, T., Yoshida, M. and Uematsu, K. (2006) Cerebellar efferent neurons in teleost fish. Cerebellum, 5, 268-274.

http://www.springerlink.com/content/h82731v07j781700

[43] Brandstätter, R. and Kotrschal, K. (1990) Brain growth patterns in four European cyprinid fish species (Cyprinidae, Teleostei): Roach (Rutilus rutilus), bream (Abramis brama), common carp (Cyprinus carpio) and sabre carp (Pelecus cultratus) Brain, Behavior and Evolution, 35, 195-211. http://www.ncbi.nlm.nih.gov/pubmed/2379081

[44] Marcus, R.C., Delaney, C.L. and Easter, S.S. (1999) Neurogenesis in the visual system of embryonic and adult zebrafish (Danio rerio) Visual Neuroscience, 16, 417424. http://www.ncbi.nlm.nih.gov/pubmed/10349963

[45] Kubota, R., Hokoc, J.N., Moshiri, A., McGuire, C. and Reh, T.A. (2002) A comparative study of neurogenesis in the retinal ciliary marginal zone of homeothermic vertebrates. Developmental Brain Research. 134, 31-41. doi:10.1016/S0165-3806(01)00287-5

[46] Rakic, P. (2004) Neuroscience: Immigration denied. Nature, 427, 685-686.

http://www.nature.com/nature/journal/v427/n6976/full/42 7685a.html

[47] Song, H., Kempermann. G., Overstreet Wadiche, L., Zhao, C., Schinder, A.F. and Bischofberger, J. (2005) New neurons in the adult mammalian brain: Synaptogenesis and functional integration. Journal of Neuroscience, 25, 10366-10368. http://www.jneurosci.org/content/25/45/10366.

[48] Lledo, P. M., Alonso, M. and Grubb, M. S. (2006) Adult neurogenesis and functional plasticity in neuronal circuits. Nature Reviews Neuroscience, 7, 179-193. http://www.nature.com/nrn/journal/v7/n3/full/nrn1867.ht $\underline{\mathrm{ml}}$. 